\title{
Structured Liquid Batteries
}

Jiajun Yan, ${ }^{[a]}$ Thomas P. Russell, ${ }^{[a, c]}$ and Brett A. Helms ${ }^{*[a, b]}$

[a] Dr. J. Yan, Prof. Dr. T. P. Russell, Dr. B. A. Helms

Materials Sciences Division

Lawrence Berkeley National Laboratory

1 Cyclotron Road Berkeley, California 94720, United States

Email: bahelms@lbl.gov

[b] Dr. B. A. Helms

The Molecular Foundry

Lawrence Berkeley National Laboratory

1 Cyclotron Road Berkeley, California 94720, United States

[c] Prof. Dr. T. P. Russell

Polymer Science and Engineering Department

University of Massachusetts

120 Governors Drive, Conte Center for Polymer Research, Amherst, Massachusetts 01003, United States 


\begin{abstract}
Chemical systems may be maintained far from equilibrium by sequestering otherwise reactive species into different microenvironments. It remains a challenge to control the amount of chemical energy stored in such systems and to utilize it on demand to perform useful work. Here, we show that redox-active molecules compartmentalized in multi-phasic structured liquid devices can be charged and discharged to power a load on an external circuit. The two liquid phases of these devices feature charge-complementary polyelectrolytes that serve a dual purpose: they generate an ionically conductive coacervate membrane at the liquid-liquid interface, providing structural support; they also mitigate active-material crossover between phases via ion-pairing with oppositely-charged anolyte and catholyte active materials. Structured liquid batteries enabled by this design were rechargeable over hundreds of hours. We envision that these devices may be integrated with soft electronics to enable functional circuits for smart textiles, medical implants, and wearables.
\end{abstract}

All-liquid batteries show tremendous versatility in form and function with the potential to power energy systems as large as the grid and as small as a wearable device. The cell chemistry for these batteries most often features high-temperature molten liquid metals, ${ }^{1}$ low-temperature eutectic alloys, ${ }^{2}$ or solutions of redox-active compounds. ${ }^{3}$ Notably, due to the conformal character of liquids, the negative and positive electrodes adopt the shape of their container, sometimes through the aid of a physical separator, or membrane; although membrane-less designs are also possible. $^{4}$ 
An emerging strategy for the creation of all-liquid devices makes use of load-bearing interfacial assemblies of polymers or nanoparticles to structure liquids into prescribed shapes such that formal containment is no longer necessary. ${ }^{5}$ Structured liquids can be patterned and printed from a broad palette of liquid media, both aqueous and non-aqueous. The membrane between the liquid phases has selective transport properties, depending on the components from which it is assembled. ${ }^{5 a, b}$ To apply this strategy to the fabrication of structured liquid batteries requires that the negative and positive electrodes be loaded with, not only charge-storing active materials, but also with components that assemble into a membrane at the liquid-liquid interface- both to support the structure of the patterned or printed all-liquid system, as well as to provide a conduit for ionic charge when the device is charged and discharged upon application of an electrochemical potential. Additional considerations arise from the need to sequester charge-storing active materials in each of the liquid phases serving as anolytes or catholytes in the device.

Here, we harness the interfacial assembly of polyelectrolytes to fabricate structured liquid batteries on hydrophobic substrates with patterned hydrophilic electrodes (Fig. 1) ${ }^{5 a}$ By controlling the geometry and surface chemistry of the current collectors, ${ }^{6}$ we can prescribe an interface between aqueous biphasic anolytes and catholytes deposited onto the electrodes (Fig. 1b). Once the interface is formed, polyanions, e.g., poly(sodium 4-styrene sulfonate), PSS-Na, dissolved in the anolyte form an ionically conductive coacervate membrane with polycations, e.g., polydiallyldimethylammonium chloride, PDADMA-Cl dissolved in the catholyte. ${ }^{5 a, 7} \mathrm{We}$ also leverage ion-pairing between polyelectrolytes and oppositely-charged charged active materials to mitigate the rate of active-material crossover between phases, allowing most of the theoretical capacity to be accessed as the device is cycled over hundreds of hours. ${ }^{9}$ 
For anolyte and catholyte phases in the device, we used the aqueous two phase system (ATPS) comprising dextran in one of the phases and poly(ethylene glycol) (PEG) in the other. ${ }^{10}$ As active materials, we used a cationic methyl viologen $(-0.45 \mathrm{~V}$ vs SHE) for the anolyte and an anionic ferrocyanide ( $0.44 \mathrm{~V}$ vs SHE) for the catholyte. Each active material is well-behaved and variants of both with different supporting salts control their solubility and reversibility in aqueous electrolytes. ${ }^{11}$ The specific counterions could influence the formation of ion-pairs with the complementary polyelectrolyte, which could be put to use in slowing the rate of crossover. ${ }^{12}$ Less clear was how specific combinations of active materials and polyelectrolytes in the ATPS influence the homogeneity of the electrolytes, electroreversibility of the active materials, and the formation rate and strength of the polyelectrolyte coacervate membrane, particularly at high salt concentrations, needed to minimize polarization in the device. 


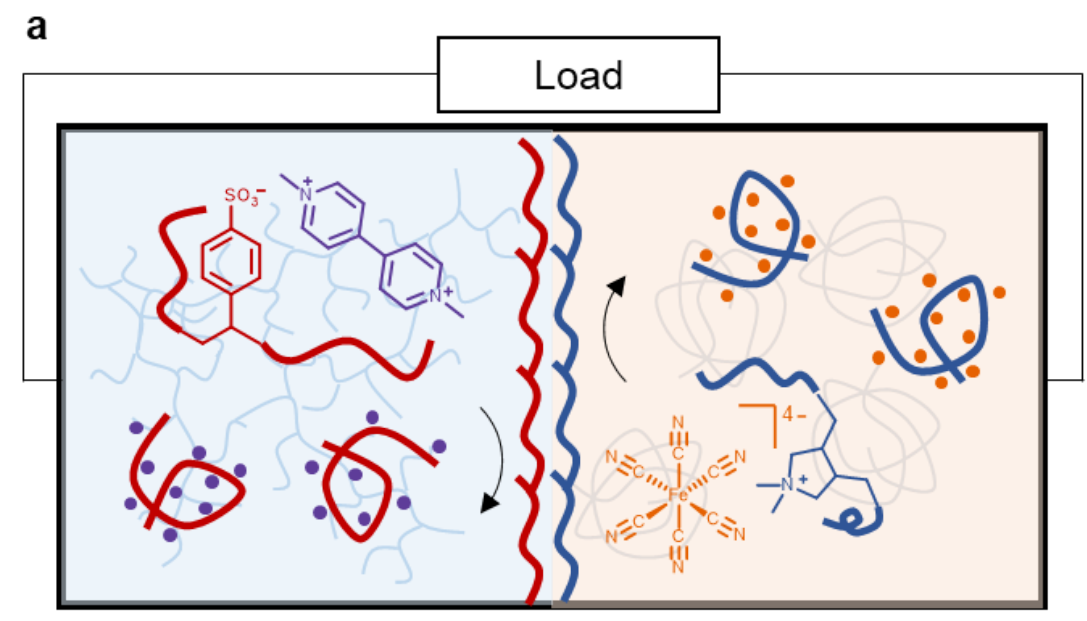

c (i)

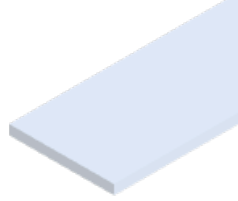

(v)

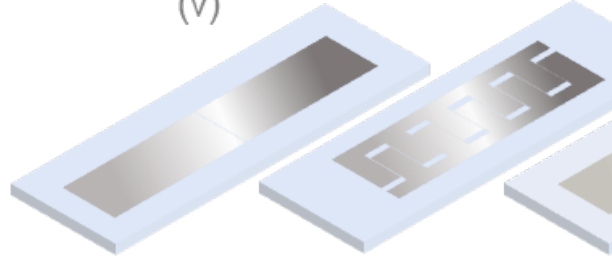

(viii)

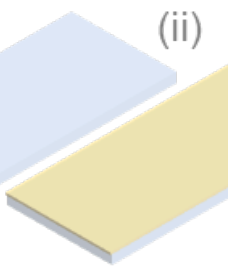

(ii)

(iii)

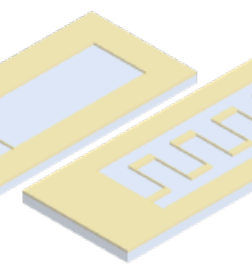

(vi)

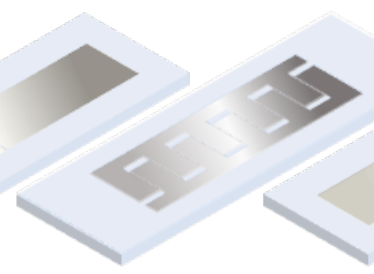

(ix)

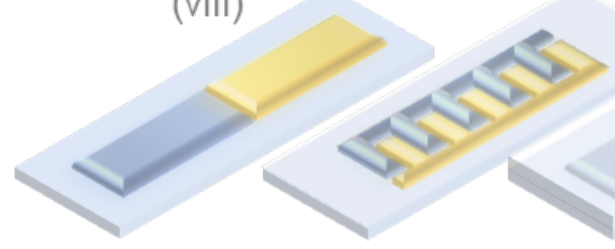

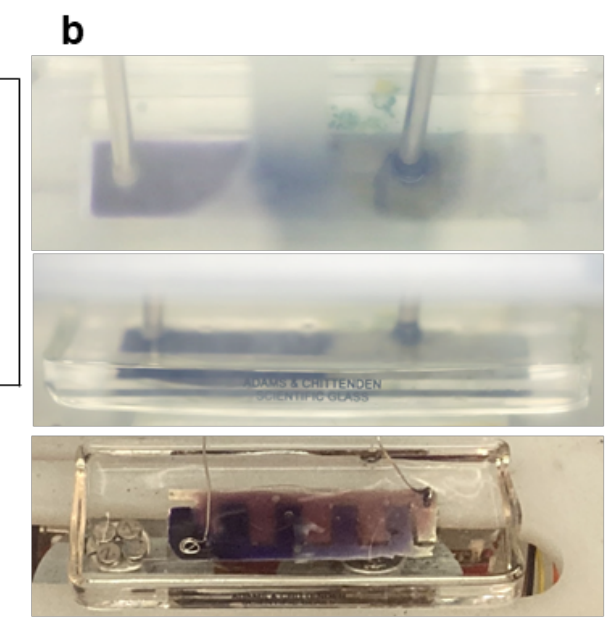

(iv)

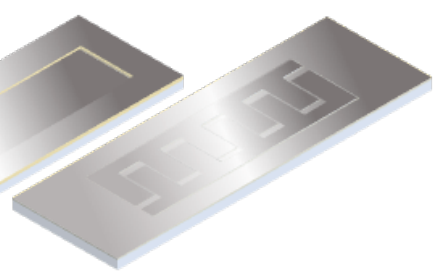

(vii)

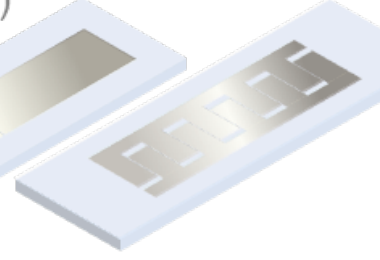

(x)

d

管 $\downarrow \mathrm{CF}_{3}\left(\mathrm{CF}_{2}\right)_{5} \mathrm{CH}_{2} \mathrm{CH}_{2} \mathrm{SiCl}_{3}$
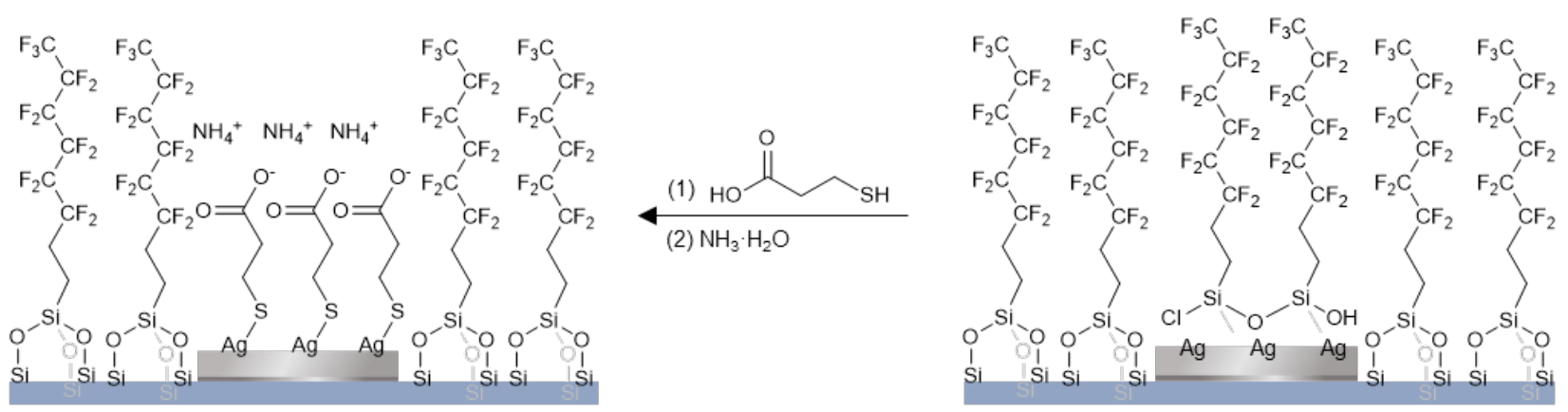
Fig. 1. Design and fabrication of under-oil structured liquid battery cells on chemically patterned glass substrates. | a, all-aqueous biphasic electrochemical cells can be fabricated from liquid electrodes based aqueous solutions of dextran and PEG. Here, the dextran-rich phase (light blue) also comprised methyl viologen (purple dots) and PSS-Na, a polyanion (red coils). The PEGrich phase (light orange) also comprised ferrocyanide (orange dots) and PDADMA-Cl, a polycation (blue coils). From PSS-Na and PDADMA-Cl, a membrane self-forms at the interface between the electrodes. b, photographs of the all-aqueous biphasic electrochemical cell during cycling. The dextran-rich phased turned dark blue, confirming the presence of the methyl viologen radical cation. c, surface patterning and device fabrication of under-oil all-aqueous biphasic electrochemical cells. Here, the oil slows the rate of evaporation of water, allowing the device to be cycled for hundreds of hours. i) UV-ozone cleaning; (ii) polyimide tape coverage; (iii) pattern inscription; (iv) Cr and Ag deposition; (v) tape removal; (vi) perfluoroalkyl treatment and washing; (vii) 2-mercaptopropionic acid treatment and neutralization; (viii) electrode printing to the confined patterns; (ix) encapsulation of the electrochemical cell under silicone oil; (x) wiring up the device with Ag wires as current collectors and introduction of the active materials. Both interdigitated array and parallel block configurations are shown and were tested. d, evolution of the surface chemistry through fabrication steps iv-vii.

We found that the composition of the supporting electrolyte strongly influenced the redox reversibility of the active materials, as well as the homogeneity of the multi-component liquid anolytes and catholytes. Initially, we examined $\mathrm{NaCl}$ as the supporting electrolyte salt, as most of the anionic and cationic electrolyte components are commonly synthesized and used with $\mathrm{Na}^{+}$and $\mathrm{Cl}^{-}$as counterions, respectively. However, we found that the electro-reversibility of ferrocyanide was poor in aqueous $\mathrm{NaCl}$ electrolytes (Fig. S1). We resolved this by using ammonium ferrocyanide in aqueous $\mathrm{NH}_{4} \mathrm{Cl}$ (Fig. 2). ${ }^{11 \mathrm{~b}}$ We then investigated the influence of $\mathrm{NH}_{4} \mathrm{Cl}$ concentration on anolyte and catholyte homogeneity (Fig. S2). At low concentrations of $\mathrm{NH}_{4} \mathrm{Cl}$, PDADMA-Cl and ammonium ferrocyanide formed a precipitate, while at high concentrations of $\mathrm{NH}_{4} \mathrm{Cl}$, mixtures of PDADMA-Cl and PEG became cloudy. Ultimately, we found that a concentration of $0.5 \mathrm{M} \mathrm{NH}_{4} \mathrm{Cl}$ afforded excellent homogeneity to both anolyte and catholyte, which then allowed us to examine the influence of all components on the redox and transport properties of the liquid electrodes. 
To assess how the electro-reversibility of methyl viologen and ferrocyanide were influenced by the increase in viscosity when dextran and PEG were present alongside chargecomplementary polyelectrolytes, we performed a series of cyclic voltammetry (CV) experiments (Fig. 2a-b). In the supporting electrolyte alone, both active materials underwent reversible redox reactions (Fig. 2a-b, S3a\&d, and S4a-b). Upon introduction of dextran $\left(M_{\mathrm{r}}=450,000-650,000\right.$; $15 \% \mathrm{w} / \mathrm{v}$ ) to methyl viologen in $0.5 \mathrm{M} \mathrm{NH}_{4} \mathrm{Cl}$, the peak currents dropped slightly (Fig. 2a\&c and S3b), resulting in a $\sim 40 \%$ decrease in the diffusion coefficient of methyl viologen (Fig. 2e and Table 1), as determined from a plot of peak current as a function of the square root of scan rates (Eq. S1). The peak separation, $\Delta E_{\mathrm{p}}$, remained almost unchanged, and the half-peak potential, $E_{\mathrm{p} / 2 \text {, }}$ shifted by $0.03 \mathrm{~V}$ (Fig. S4a\&c). Similarly, upon introduction of PEG $\left(M_{\mathrm{n}}=20,000 ; 10 \% \mathrm{w} / \mathrm{v}\right)$ to ferrocyanide in $0.5 \mathrm{M} \mathrm{NH}_{4} \mathrm{Cl}$, the peak current and diffusion coefficient dropped by $\sim 40 \%$ (Fig. 2b\&d-e, S3e, and Table 1). $\Delta E_{\mathrm{p}}$ remained largely unchanged, while $E_{\mathrm{p} / 2}$ shifted by $-0.21 \mathrm{~V}$ (Fig. S4b\&d).

Table 1. Electrochemical and Diffusion Properties of Active Materials

\begin{tabular}{|c|c|c|c|c|}
\hline $\begin{array}{l}\text { Active } \\
\text { species }\end{array}$ & Medium & $\begin{array}{ll}E_{\mathrm{p} / 2} & \mathrm{vs} \\
\operatorname{AgCl} / \operatorname{Ag}(V){ }^{a}\end{array}$ & $D_{c}\left(\mathrm{~cm}^{2} \mathrm{~s}^{-1}\right)^{\mathrm{b}}$ & $D_{\mathrm{a}}\left(\mathrm{cm}^{2} \mathrm{~s}^{-1}\right)^{\mathrm{b}}$ \\
\hline \multirow{3}{*}{$\mathbf{M V}^{2+}$} & $\mathrm{NH}_{4} \mathrm{Cl}$ & -0.612 & $4.59 \times 10^{-6}$ & $5.28 \times 10^{-6}$ \\
\hline & $\mathrm{NH}_{4} \mathrm{Cl}+$ dextran & -0.609 & $2.90 \times 10^{-6}$ & $3.15 \times 10^{-6}$ \\
\hline & $\mathrm{NH}_{4} \mathrm{Cl}+$ dextran+PSS & -0.599 & $8.68 \times 10^{-7}$ & $5.03 \times 10^{-7}$ \\
\hline \multirow{3}{*}{$\mathrm{Fe}(\mathrm{CN})_{6}^{4-}$} & $\mathrm{NH}_{4} \mathrm{Cl}$ & 0.249 & $1.10 \times 10^{-6}$ & $1.54 \times 10^{-6}$ \\
\hline & $\mathrm{NH}_{4} \mathrm{Cl}+\mathrm{PEG}$ & 0.228 & $5.97 \times 10^{-7}$ & $9.82 \times 10^{-7}$ \\
\hline & $\mathrm{NH}_{4} \mathrm{Cl}+\mathrm{PEG}+\mathrm{PDADMA}$ & 0.179 & $2.56 \times 10^{-7}$ & $5.46 \times 10^{-7}$ \\
\hline
\end{tabular}

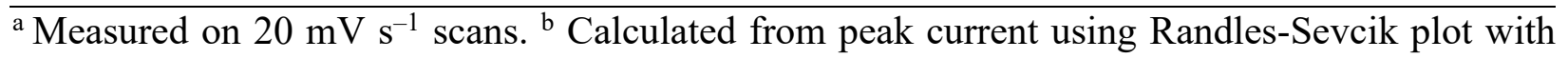
Ordinary Least Squares regression. 
While viscosity played a role in modulating the electro-reversibility of active materials in ATPSs containing high concentrations of electrolyte, so did the addition of polyelectrolytes with complementary charge. Specifically, when polyanionic PSS-Na $\left(M_{\mathrm{w}}=70,000 ; 1 \% \mathrm{w} / \mathrm{v}\right)$ was added to methyl viologen in $15 \%$ dextran and $0.5 \mathrm{M} \mathrm{NH}_{4} \mathrm{Cl}$, the peak currents and diffusion coefficients were further reduced; especially the anodic peak current, which dropped by approximately one order of magnitude (Fig. 2a,c,e, S3c, and Table 1). The disparity in changes between anodic and cathodic peak currents reflect the different states-of-charge of the active material in the forward and reverse electrochemical reactions, which direct the electrostatic interactions in the system between the active material and the polyelectrolyte, and, therefore, the structure of the supramolecular redoxmer and its interaction with the current collector during electron transfer. Meanwhile, both $\Delta E_{\mathrm{p}}$ and $E_{\mathrm{p} / 2}$ increased slightly (Fig. S4a\&c). Similarly, upon introduction of polycationic PDADMA-Cl $\left(M_{\mathrm{w}}=200,000-350,000 ; 1 \% \mathrm{w} / \mathrm{v}\right)$ to ammonium ferrocyanide in $10 \%$ PEG and $0.5 \mathrm{M} \mathrm{NH}_{4} \mathrm{Cl}$, the peak current and diffusion coefficient were also lowered (Fig. 2b,d\&e, S3e, and Table 1). The cathodic peak current dropped by $\sim 60 \%$, while the anodic peak currents dropped by $\sim 40 \%$. Meanwhile, $\Delta E_{\mathrm{p}}$ also increased slightly, while $E_{\mathrm{p} / 2}$ dropped by $0.049 \mathrm{~V}$ (Fig. S4a\&c). Therefore, while dextran and PEG impact electro-reversibility and self-diffusion of the active materials due to the increase in viscosity, this behavior, along with the electrostatic interactions between charge-complementary polyelectrolytes and actives, are compounded in their influence on those characteristics. We find that electrochemistry is remarkably precise in revealing and quantifying the impact of the state-of-charge-dependent supramolecular (i.e., electrostatic) interactions between polyelectrolytes and the active materials on charge transfer processes between these supramolecular redoxmers and the electrodes. 

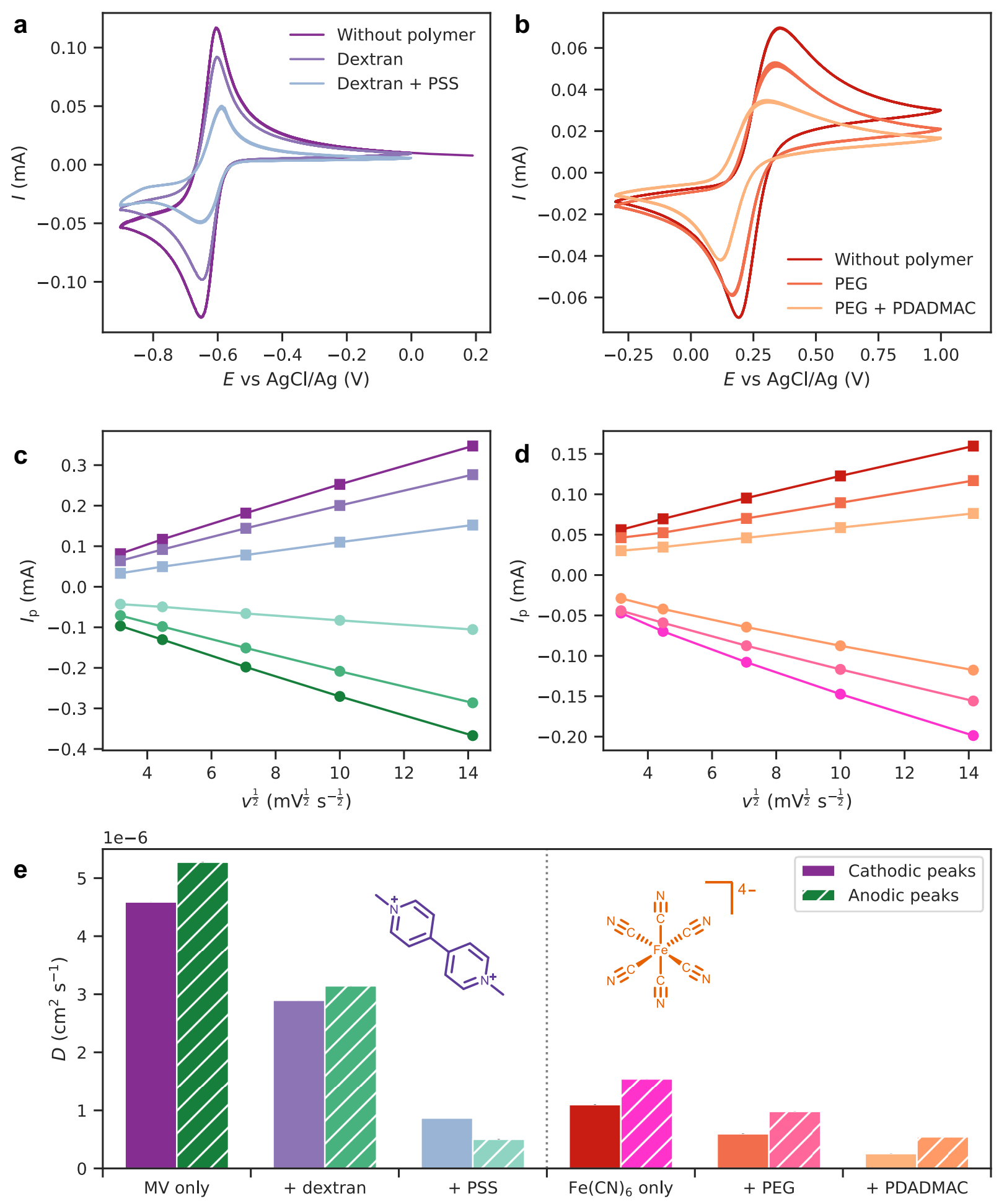

Fig. 2. Quantifying the impacts of electrostatic interactions and electrode formulation on electrochemical behavior. | a, cyclic voltammetry of methyl viologen without polymers, in $15 \%$ dextran, or in $15 \%$ dextran and $1 \%$ PSS at $20 \mathrm{mV} \mathrm{s}^{-1}$. $\mathbf{b}$, cyclic voltammetry of ferrocyanide without polymers, in $10 \%$ PEG, or in $10 \%$ PEG and $1 \%$ PDADMA at $20 \mathrm{mV} \mathrm{s}^{-1}$. c, RandlesSevcik plot of the cathodic and anodic peak currents of methyl viologen. d, Randles-Sevcik plot 
of the cathodic and anodic peak currents of ferrocyanide. e, diffusion coefficients calculated using ordinary least squares linear regression and half-peak potentials of the active species with or without the polymers. Cyclic voltammetry performed using a 3-mm glassy carbon working electrode, a 3.0 M NaCl AgCl/Ag reference electrode, and a Pt counter electrode.

Membrane formation and stability are critically important when fabricating structured liquid devices. When fabricating structured liquid batteries, high concentrations of salt relative to the active materials in the electrolyte are needed to minimize cell polarization during charge and discharge. Yet, membrane formation from polyelectrolytes at a liquid-liquid interface is known to be inhibited by salt. We confirmed this by showing that PSS-PDADMA films do not form instantaneously at a water-water interface at high salt concentrations. ${ }^{5 a}$ We considered alternatives, including a PSS-poly(allylamine) coacervate film, whose formation has been shown to be less sensitive to high salt concentration. However, we found that the primary amines of poly(allylamine) were redox active. We then considered whether PSS-PDADMA coacervate films could form at all at high salt concentrations. ${ }^{13}$ We constructed a bulk prototype of all-aqueous biphasic electrochemical cell to study the rate of coacervate membrane formation over time and tested its stability. After $24-48 \mathrm{~h}$, we found that the coacervate membrane was visible and capable of limiting diffusion of methyl viologen radical cations (Fig. S5a), confirming membrane formation. After four days, the membrane was sufficiently strong to hold $10 \mathrm{~mL}$ of aqueous solution upon inversion of the crude bilayer cell (Fig. S5b). This indicated that while high salt concentration in the electrodes slows the formation of the membrane, once formed, it is strong and can support the device structure indefinitely. These data also indicated that cell fabrication must take into account the rate of membrane formation prior to the introduction of the active materials to take maximum benefit of membrane blocking. 
Having established an understanding of the formulation of anolytes and catholytes to enable redox reversibility, active material complexation to the endogenous polyelectrolytes through ion-pairing, and coacervate membrane formation at the liquid-liquid interface from charge-complementary polyelectrolytes, we next sought to implement the all-aqueous biphasic liquid electrodes in patterned and printed electrochemical devices. To do so, we designed a fabrication strategy for depositing current collectors on a glass slide, where the current collectors were rendered hydrophilic, while the surrounding glass surface was made hydrophobic. This wetting condition ensured that the printed electrodes were confined to the boundaries set by the current collector. We tested two types of patterned current collectors: parallel plates and interdigitated arrays (Fig. S6). We thermally evaporated metallic silver onto the glass surface, using chromium as the adhesion layer (Fig. 1c).${ }^{14} \mathrm{We}$ then applied a perfluoroalkyl trichlorosilane monolayer to the entire substrate. To displace the perfluoroalkyl monolayer on silver, we introduced mercaptopropionic acid, which forms stronger bounds to the surface via thiolate linkages. We then neutralized the acid by using an aqueous ammonia solution (Fig. 1d). By this method, we produced superhydrophobic glass surfaces on which patterned silver current collectors are hydrophilic and salt-matched to the electrolyte used in the devices.

We found that the efficacy of electrode wetting with either of the aqueous bi-phasic electrolytes depended strongly on the geometry of the patterned electrode. Initially, an interdigitated array with prototypical thin fingers connected to two large reservoirs was used (Fig. S7). However, the Laplace pressure drove the liquids from the fingers to the reservoirs. ${ }^{6}$ Consequently, an interdigitated array with thick fingers was designed and fabricated (Fig. S6b). The two electrode designs shared a similar surface area $\left(8.04 \mathrm{~cm}^{2} \mathrm{vs} 7.97 \mathrm{~cm}^{2}\right)$, but the boundaries between the current collectors were different $(12.7 \mathrm{~mm}$ vs. $120 \mathrm{~mm})$. Therefore, the interface-to- 
volume ratios were distinct as well $\left(0.158 \mathrm{~cm}^{-1}\right.$ vs. $\left.1.51 \mathrm{~cm}^{-1}\right)$, which translated into a difference in areal density of polyelectrolytes $\left(63 \mathrm{mg} \mathrm{cm}^{-2}\right.$ vs. $\left.6.6 \mathrm{mg} \mathrm{cm}^{-2}\right)$ and accessible membrane thickness. By increasing the volume of anolyte and catholyte applied to the electrodes, we were able to confidently establish the interface between them, which initiated membrane formation. We found that the self-forming membrane impeded mass transfer between the two phases, as shown by the dark blue methyl viologen radical cations in Fig. 1b. ${ }^{5 a}$ To limit the extent of evaporation, we implemented a simple "under-oil" approach, covering the entire device with a layer of silicone oil with a viscosity of $10 \mathrm{cSt} .{ }^{16}$

Having established the means to pattern and print all-aqueous biphasic devices with selfforming polyelectrolyte-based coacervate membranes and ensure the longevity of the device by controlling the rate of evaporation of water, we then demonstrated that the device could be driven in and out of chemical equilibrium by the application of an electrochemical potential, where current flowed through an external circuit as the active materials in the anolyte and catholyte were charged and discharged. We galvanostatically cycled a device featuring parallel electrodes at a $\mathrm{C} / 5$ rate $(54 \mu \mathrm{A})$ for $884 \mathrm{~h}($ Fig. 3a). In each cycle, we used a constant current charge and a constant current-constant voltage (CCCV) discharge to access the full capacity of the electrodes (Fig. 3c). The charge and discharge curves plateaued at $\sim 0.65 \mathrm{~V}$ and $\sim 0.55 \mathrm{~V}$, respectively (Fig. 3b-c), lower than the $E_{\mathrm{p} / 2}$ difference of $0.78 \mathrm{~V}$ (Fig. 2e and Table 11), suggesting a potential drop at the interface of the current collector with the liquid electrodes. ${ }^{17}$ Despite this, the device accessed $100 \%$ of its theoretical capacity within 4 cycles and was stable for $430 \mathrm{~h}$. Due to the formation of ionpolyelectrolyte complexes, vide supra, diffusion of active materials was considerably slower in this cell. Consequently, only a fraction of the active materials in the proximity of the current collector was initially charged, however, diffusion of the supramolecular redoxmer complexes and 
self-exchange of electrons allowed active materials farther away from the current collector to undergo redox reactions (Fig. S8). During the discharge process, supramolecular redoxmers close to the current collectors were quickly discharged leading to a rapid decrease in voltage when approximately half of the capacity discharged. Nevertheless, the remaining capacity was still accessible over time with a constant voltage discharge at $0.2 \mathrm{~V}$ by diffusion and self-exchange (Fig. 3c). Cells showed a relatively low Coulombic efficiency, which gradually increased over time (Fig. 3d).

Beginning with the $30^{\text {th }}$ cycle, the capacity began to decrease. During this time, the Coulombic efficiency rose above $100 \%$, which is generally indicative of side reactions. Indeed, beginning in $25^{\text {th }}$ cycle, the discharge curves showed a secondary plateau consistent with a new species undergoing reduction (Fig. 3c). This new feature in the discharge curves may arise from redox active species in the wrong electrode compartment resulting from crossover evident when operating the device over long periods of time. Notably, the association of active materials with charge-complementary polyelectrolytes is in dynamic equilibrium. This equilibrium is influenced by the state of charge of the electrode, as ion-pairing strength will depend on the redox state of the active material. If at a specific state of charge, the strength of ion-pairing is low and ion-separated pairs are more prevalent, this could lead to increased rates of crossover as the effective size of the redox-active species is that of the small molecule and no longer that of the much larger supramolecule. Alternatively, the capacity fade may be tied to slow but cumulative effects of evaporation from the electrodes. ${ }^{16}$ In comparison to the parallel plate electrode geometry, devices featuring interdigitated array electrodes showed significantly poorer cyclability due, more than likely, to the larger interfacial area and thinner membrane, both of which influence the rate of 
crossover (Fig. S9 and Fig. 1b). In this way, we reasoned that crossover, rather than evaporation, was the most likely explanation for the observed capacity fade.

a

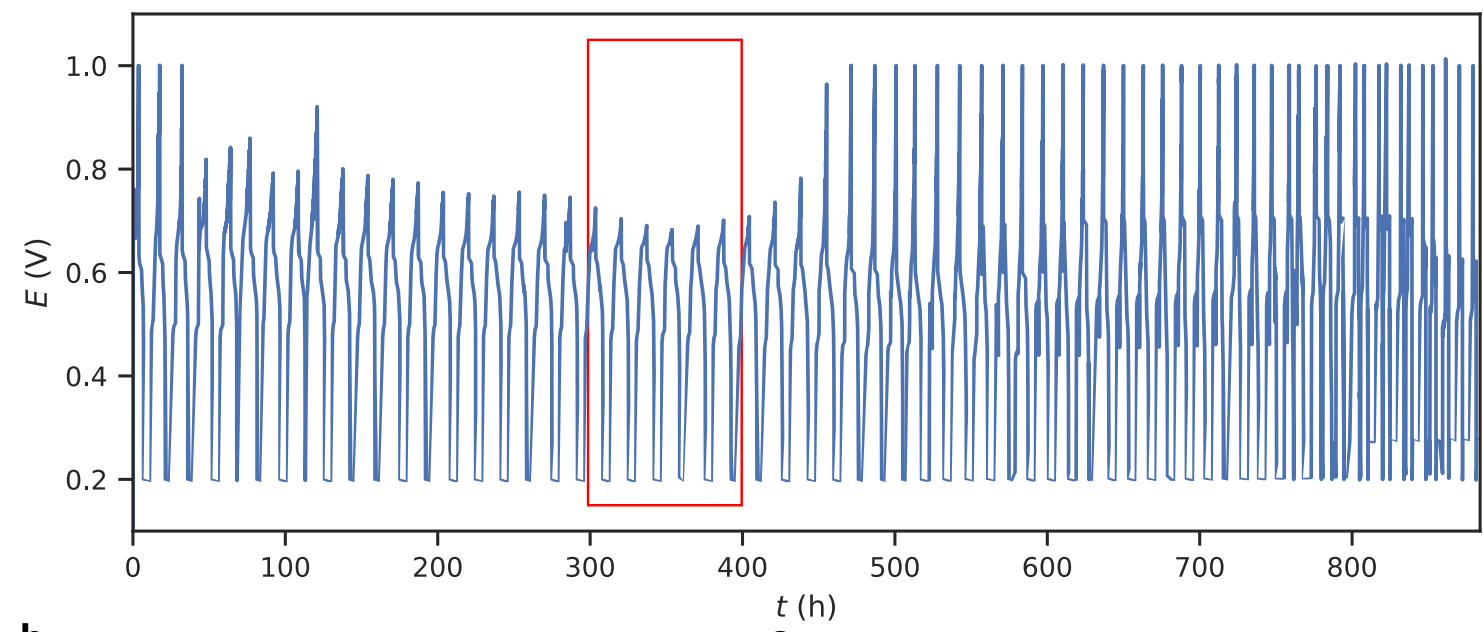

b

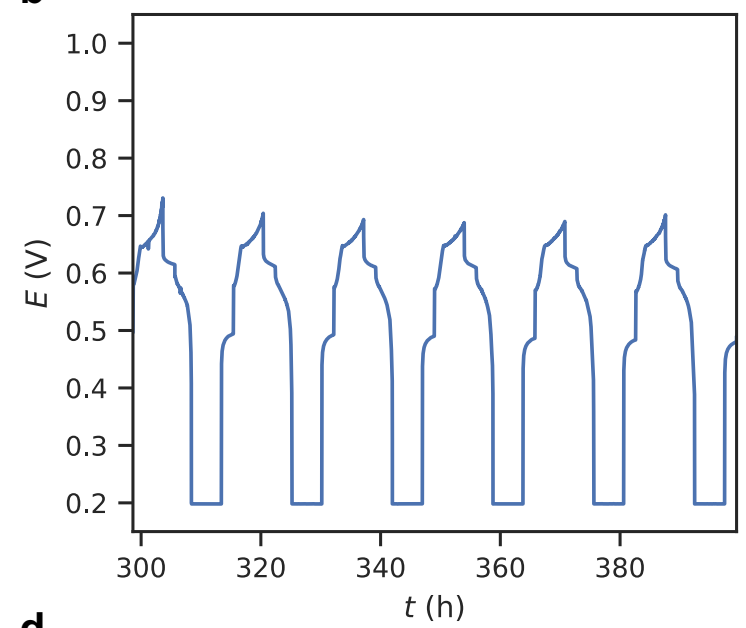

c

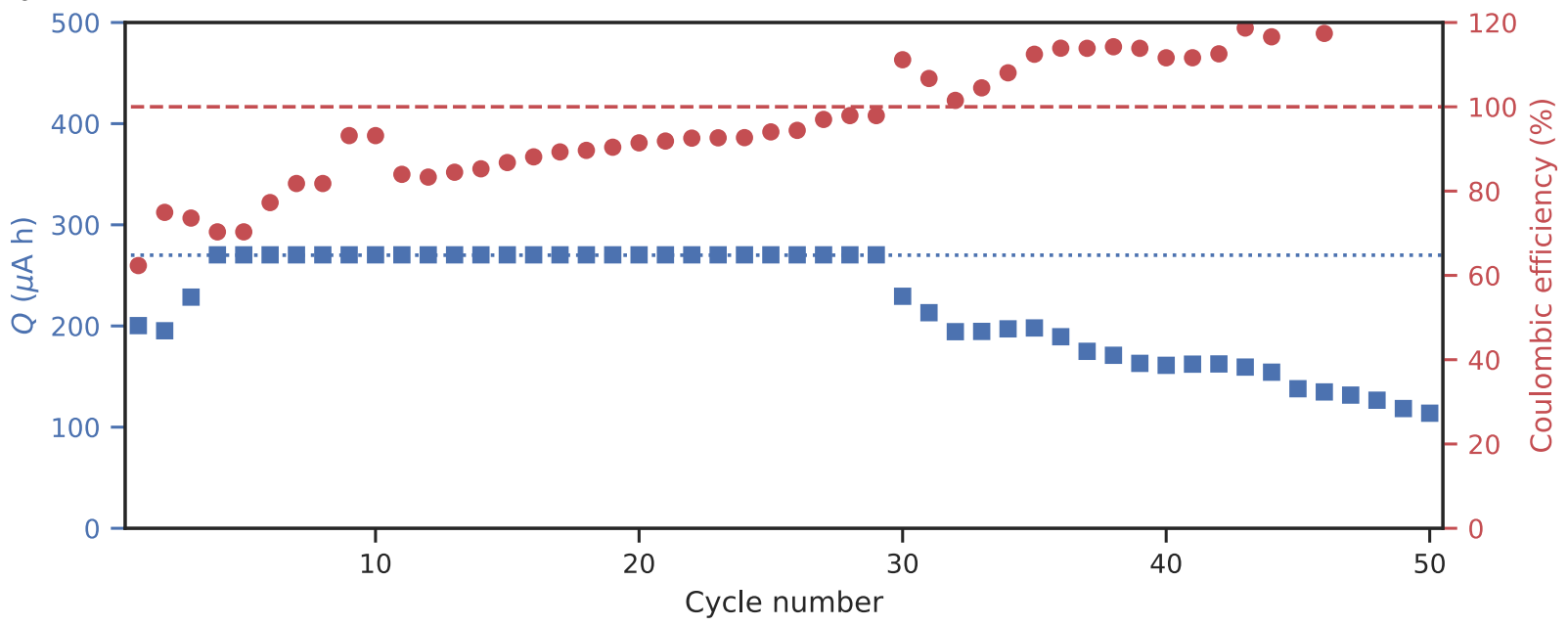


Fig. 3. Full cell cycling of an under-oil structured liquid battery cell | a, full cell charge/discharge of the under-oil all-aqueous electrochemical cell. b, an excerpt of cycles 20-25 (indicated as a red box in Panel a). c, charge and discharge potential vs capacity in cycles 10, 20, 30, 40, and 50. d, Columbic efficiency and accessed capacity of each cycle. The red dashed line indicates the theoretical capacity. In each cycle, the cell was charged/discharged at a constant current of $54 \mu \mathrm{A}$ up to the potential limits of $1.0 \mathrm{~V}$ and $0.2 \mathrm{~V}$, respectively, or up to $5 \mathrm{~h}$. A constant voltage discharge for up to $5 \mathrm{~h}$ with a cutoff current of $3 \mu \mathrm{A}$. After charge/discharge, the cell was rested for $2 \mathrm{~h}$.

To confirm this, we quantified the extent of crossover by measuring the concentrations of active materials in each phase. After siphoning off the silicone oil, we retrieved the cell and allowed the water to evaporate, leaving behind films of polymer, salt, and actives on each of the current collectors. We carefully retrieved the contents from each phase, diluting them in $0.5 \mathrm{M}$ $\mathrm{NH}_{4} \mathrm{Cl}$ prior to analysis by $\mathrm{CV}$ (Fig. S10). The methyl viologen concentration in the PEG phase and the ferrocyanide concentration in the dextran phase were then measured electrochemically against calibration curves using the cathodic peak current of methyl viologen and the anodic peak current of ferrocyanide to avoid interference from oxygen/hydrogen evolution reactions. We found that $\sim 12 \%$ of the methyl viologen and $\sim 20 \%$ of the ferrocyanide diffused across the coacervate membrane after $24 \mathrm{~h}$ of annealing and $884 \mathrm{~h}$ of cycling.

With these data, we estimated the membrane blocking ability. To calculate the diffusive permeability of each active material across the PSS-PDADMA coacervate membrane, $D_{\text {eff, }}$ requires that the initial and permeated concentration of active materials is known alongside the total electrolyte volume, the total time during which the actives were in contact with the membrane, as well as the surface area and thickness of the membrane (Eq. S2). ${ }^{11 a}$ While these variables are known or were determined, the thickness of the membrane was difficult to measure, as it selfforms with relatively small area at a liquid-liquid interface at an orientation that is normal to the 
plane of the underlying substrate. Elsewhere, the thickness of PSS-PDADMA coacervate films assembled layer-by-layer at a salt concentration of $0.5 \mathrm{M}$ reached up to $500 \mathrm{~nm}$ for 30 layers. ${ }^{18}$ Absent the layer-by-layer technique, PSS-PDADMA coacervate membranes are not usually as thick: ${ }^{5 a}$ Scanning electron micrographs of a PSS-PDADMA assembly, similar to the one explored here, were only a few hundred nanometers thick. ${ }^{19}$ Even if we assume that the PSS-PDADMA membrane was 500-nm thick, $D_{\text {eff }}$ can be no more than $5.8 \times 10^{-12} \mathrm{~cm}^{2} \mathrm{~s}^{-1}$ and $9.6 \times 10^{-12} \mathrm{~cm}^{2} \mathrm{~s}^{-1}$ for methyl viologen and ferrocyanide, respectively. Therefore, the membrane blocking ability,

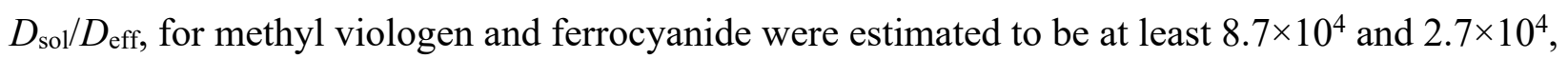
respectively; $D_{\text {sol }}$ values were taken from polyelectrolyte complexes of the uncharged species taken in either dextran or PEG aqueous electrolyte phases (Table 1). This is remarkable in that values of $D_{\text {sol }} / D_{\text {eff }}>10^{4}$ are rare for membranes and small molecule active materials, more often requiring conformationally rigid microporous and nanoporous polymer membranes, whose voids are on the same length scale as the solvated actives. ${ }^{3 \mathrm{c}, 11 \mathrm{a}}$

Our results demonstrate that it is now possible to precisely define the electrochemical potential in compartmentalized chemical systems comprising multi-phasic liquids that are printed or patterned in arbitrary shapes and forms, provided they meet at an interface. We are able to maintain such systems far from chemical equilibrium by controlling the rates of mass transfer between the two liquid phases. We achieved this by increasing the effective size of the active materials through ion-pairing with charge-complementary polyelectrolytes, and by blocking the crossover of these supramolecular redoxmers with polyelectrolyte coacervate membranes that selfform at the interface between the liquid phases. In the absence of such control, the stored chemical energy would normally be dissipated internally through cross-annihilation via redox reactions. With this control, it becomes possible to harness the stored chemical energy to perform useful 
work, e.g., powering a load on an external circuit as the structured liquid battery is discharged.

This behavior, which has been realized here in an artificial synthetic system with broad tunability, is reminiscent of biological systems that stay out of equilibrium by compartmentalizing function in both membrane-bound and membrane-less organelles, ${ }^{20}$ allowing them to adapt and respond to local chemical and environmental cues as well as various physical stimuli.

\section{References}

1. a) K. Wang, K. Jiang, B. Chung, T. Ouchi, P. J. Burke, D. A. Boysen, D. J. Bradwell, H. Kim, U. Muecke, D. R. Sadoway, Nature 2014, 514, 348-350; b) D. J. Bradwell, H. Kim, A. H. C. Sirk, D. R. Sadoway, J. Am. Chem. Soc. 2012, 134, 1895-1897.

2. a) Y. Ding, X. Guo, Y. Qian, L. Xue, A. Dolocan, G. Yu, Adv. Mater. 2020, 32, e2002577; b) Y. Ding, X. Guo, G. Yu, ACS Cent Sci 2020, 6, 1355-1366; c) L. Xue, H. Gao, W. Zhou, S. Xin, K. Park, Y. Li, J. B. Goodenough, Adv. Mater. 2016, 28, 9608-9612; d) S. Li, H. Wang, J. Cuthbert, T. Liu, J. F. Whitacre, K. Matyjaszewski, Joule 2019, 3, 1637-1646.

3. a) W. Wang, Q. Luo, B. Li, X. Wei, L. Li, Z. Yang, Adv. Funct. Mater. 2013, 23, 970-986; b) K. H. Hendriks, S. G. Robinson, M. N. Braten, C. S. Sevov, B. A. Helms, M. S. Sigman, S. D. Minteer, M. S. Sanford, ACS Cent Sci 2018, 4, 189-196; c) M. J. Baran, M. N. Braten, S. Sahu, A. Baskin, S. M. Meckler, L. Li, L. Maserati, M. E. Carrington, Y.-M. Chiang, D. Prendergast, B. A. Helms, Joule 2019, 3, 2968-2985.

4. a) P. Navalpotro, J. Palma, M. Anderson, R. Marcilla, Angew. Chem. Int. Ed Engl. 2017, 56, 12460-12465; b) W. A. Braff, M. Z. Bazant, C. R. Buie, Nat. Commun. 2013, 4, 2346; c) I. Karakurt, J. Elwood, X. Li, L. Beker, E. Sweet, W. Cai, L. Lin, in 2017 19th International Conference on Solid-State Sensors, Actuators and Microsystems (TRANSDUCERS), Ieeexplore.ieee.org, 2017, pp. 1820-1823; d) J. Meng, Q. Tang, L. Zhou, C. Zhao, M. Chen, Y. Shen, J. Zhou, G. Feng, Y. Shen, Y. Huang, Joule 2020, 4, 953-966; e) Cho, S.-J., Jung, G.Y., Kim, S.H., Jang, M., Yang, D.-K., Kwak, S.K., and Lee, S.-Y. (2019). Monolithic heterojunction quasi-solid-state battery electrolytes based on thermodynamically immiscible dual phases. Energy Environ. Sci. 12, 559-565.

5. a) G. Xie, J. Forth, Y. Chai, P. D. Ashby, B. A. Helms, T. P. Russell, Chem 2019, 5, 2678-2690; b) W. Feng, Y. Chai, J. Forth, P. D. Ashby, T. P. Russell, B. A. Helms, Nat. Commun. 2019, 10, 1095; c) Forth, J.; Kim, P. Y.; Xie, G.; Liu, X.; Helms, B. A.; Russell, T. P. Adv. Mater. 2019, 31, 1806370; d) X. Liu, N. Kent, A. Ceballos, R. Streubel, Y. Jiang, Y. Chai, P. Y. Kim, J. Forth, F. Hellman, S. Shi, D. Wang, B. A. Helms, P. D. Ashby, P. Fischer, T. P. Russell, Science 2019, 365, 264-267; e) M. Cui, T. Emrick, T. P. Russell, Science 2013, 342, 460-463; f) A. J. Liu, S. R. Nagel, Nature 1998, 396, 21-22.

6. a) L. Wu, Z. Dong, F. Li, Y. Song, Langmuir 2018, 34, 639-645; b) J. M. Scheiger, M. A. Kuzina, M. Eigenbrod, Y. Wu, F. Wang, S. Heißler, S. Hardt, B. Nestler, P. A. Levkin, $A d v$. Mater. 2021, e2100117. 
7. Q. Wang, J. B. Schlenoff, Macromolecules 2014, 47, 3108-3116.

8. a) Y. Tran, P. Auroy, L. T. Lee, M. Stamm, Phys. Rev. E Stat. Phys. Plasmas Fluids Relat. Interdiscip. Topics 1999, 60, 6984-6990; b) D. Volodkin, R. von Klitzing, Curr. Opin. Colloid Interface Sci. 2014, 19, 25-31.

9. a) K. W. Knehr, E. Agar, C. R. Dennison, A. R. Kalidindi, E. C. Kumbur, J. Electrochem. Soc. 2012, 159, A1446; b) J. grosse Austing, C. Nunes Kirchner, L. Komsiyska, G. Wittstock, J. Power Sources 2016, 306, 692-701; c) R. Darling, K. Gallagher, W. Xie, L. Su, F. Brushett, J. Electrochem. Soc. 2015, 163, A5029.

10. a) P. A. Albertsson, Nature 1958, 182, 709-711; b) J. Ryden, P.-A. Albertsson, J. Colloid Interface Sci. 1971, 37, 219-222; c) A. D. Diamond, J. T. Hsu, Biotechnol. Tech. 1989, 3, 119124.

11. a) T. Liu, X. Wei, Z. Nie, V. Sprenkle, W. Wang, Adv. Energy Mater. 2016, 6, 1501449; b) J. Luo, B. Hu, C. Debruler, Y. Bi, Y. Zhao, B. Yuan, M. Hu, W. Wu, T. L. Liu, Joule 2019, 3, 149163; c) B. Hu, C. DeBruler, Z. Rhodes, T. L. Liu, J. Am. Chem. Soc. 2017, 139, 1207-1214; d) X. Wei, G.-G. Xia, B. Kirby, E. Thomsen, B. Li, Z. Nie, G. G. Graff, J. Liu, V. Sprenkle, W. Wang, J. Electrochem. Soc. 2015, 163, A5150.

12. a) S. E. Doris, A. L. Ward, A. Baskin, P. D. Frischmann, N. Gavvalapalli, E. Chénard, C. S. Sevov, D. Prendergast, J. S. Moore, B. A. Helms, Angew. Chem. Int. Ed. 2017, 56, 1595-1599; b) G. S. Manning, J. Chem. Phys. 1969, 51, 934-938; c) Y. Y. Lai, X. Li, Y. Zhu, ACS Appl. Polym. Mater. 2020, 2, 113-128.

13. S. T. Dubas, J. B. Schlenoff, Macromolecules 1999, 32, 8153-8160.

14. P. Benjamin, C. Weaver, Proc. R. Soc. Lond. A Math. Phys. Sci. 1961, 261, 516-531.

15. C. Li, Z. Hite, J. W. Warrick, J. Li, S. H. Geller, V. G. Trantow, M. N. McClean, D. J. Beebe, Sci $A d v 2020,6$, eaay9919.

16. W. L. Robb, Ann. N. Y. Acad. Sci. 1968, 146, 119-137.

17. Verwey, E. J. W. \& Niessen, K. F. XL. The electrical double layer at the interface of two liquids. The London, Edinburgh, and Dublin Philosophical Magazine and Journal of Science 28, 435-446 (1939)

18. a) E. Guzmán, H. Ritacco, J. E. F. Rubio, R. G. Rubio, F. Ortega, Soft Matter 2009, 5, 2130; b) J. J. Iturri Ramos, S. Stahl, R. P. Richter, S. E. Moya, Macromolecules 2010, 43, 9063-9070.

19. G. Xie, J. Forth, S. Zhu, B. A. Helms, P. D. Ashby, H. C. Shum, T. P. Russell, Proc. Natl. Acad. Sci. U. S. A. 2020, 117, 8360-8365.

20. a) A. A. Hyman, C. A. Weber, F. Jülicher, Annu. Rev. Cell Dev. Biol. 2014, 30, 39-58; b) D. M. Mitrea, R. W. Kriwacki, Cell Commun. Signal. 2016, 14, 1; c) S. Boeynaems, S. Alberti, N. L. Fawzi, T. Mittag, M. Polymenidou, F. Rousseau, J. Schymkowitz, J. Shorter, B. Wolozin, L. Van Den Bosch, P. Tompa, M. Fuxreiter, Trends Cell Biol. 2018, 28, 420-435; d) R. J. Wheeler, A. A. Hyman, Philos. Trans. R. Soc. Lond. B Biol. Sci. 2018, 373, DOI 10.1098/rstb.2017.0193; e) B. Wolozin, P. Ivanov, Nat. Rev. Neurosci. 2019, 20, 649-666; f) E. Gomes, J. Shorter, J. Biol. Chem. 2019, 294, 7115-7127; g) B. G. O’Flynn, T. Mittag, Curr. Opin. Cell Biol. 2021, 69, 70 79. 


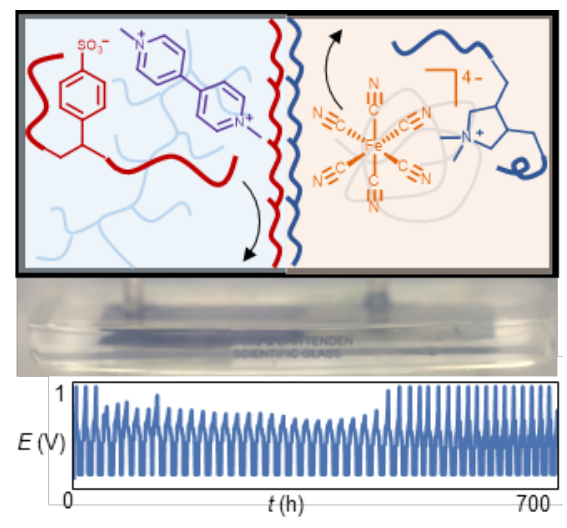

Here we describe structured liquid batteries, whose membranes self-form via coacervation of polyelectrolytes. The membrane serves as an ion conductor, a physical barrier, and a structural support. Complexation of redox-active small molecules with their complementary

polyelectrolyte also mitigates the crossover. The reconfigurability of liquids allows the cell to conform to prescribed patterns and the cells are rechargeable for hundreds of hours. 


\section{Supplementary Information}

\section{Structured Liquid Batteries}

Jiajun Yan, Thomas P. Russell, Brett A. Helms*

\section{Table of Contents}

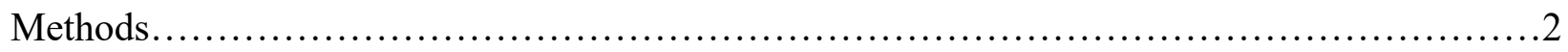

Fig. S1. Redox reversibility of ferrocyanide...........................................

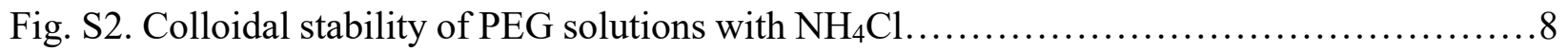

Fig. S3. Cyclic voltammetry experiments...................................... 9

Fig. S4. Cathodic and anodic peak potentials of the active materials with or without polymer

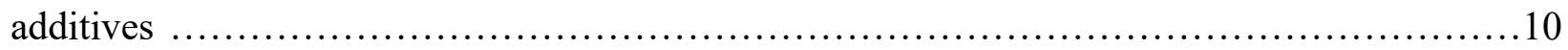

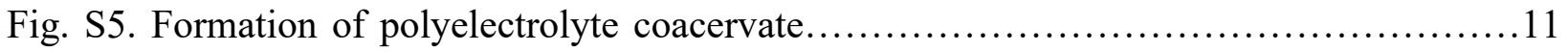

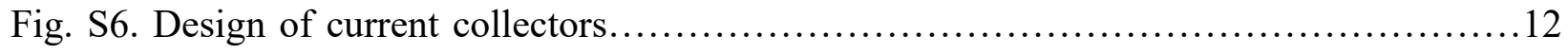

Fig. S7. Wetting on conventional interdigitated array................................... 13

Fig. S8. Illustration of the evolution of active material complexes in a cell...................14

Fig. S9. Under-oil all-aqueous electrochemical cell with an interdigitated array

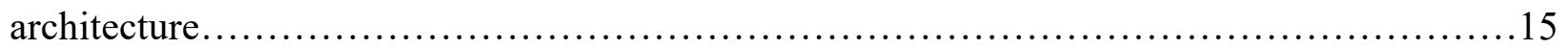

Fig. S10. Crossover analysis after cycling ........................................ 16

Table S1. Electrochemical and Diffusion Properties of Active Materials......................17

References.................................................................... 16 


\section{Methods}

\section{Materials}

Dextran from Leuconostoc spp. (Aldrich, $M_{\mathrm{r}}$ 450,000-650,000), poly(ethylene glycol) (PEG, Aldrich, $M_{\mathrm{n}}$ 20,000), sodium ferrocyanide decahydrate $\left(\mathrm{Na}_{4} \mathrm{Fe}(\mathrm{CN})_{6} \cdot 10 \mathrm{H}_{2} \mathrm{O}\right.$, Aldrich, 99\%), methyl viologen dicholoride hydrate (MV, Aldrich, 98\%), poly(sodium 4-styrenesulfonate) (PSSNa, Aldrich, $\left.M_{\mathrm{w}} 70,000\right)$, poly(diallyldimethylammonium chloride) (PDADMA-Cl, Aldrich, $M_{\mathrm{w}}$ 200,000-350,000), ammonium chloride $\left(\mathrm{NH}_{4} \mathrm{Cl}\right.$, Aldrich, 99.5\%), trichloro $(1 H, 1 H, 2 H, 2 H$ perfluoro)octylsilane (PFOTS, Aldrich, 97\%), 3-mercaptopropionic acid (Aldrich, 99\%), hexanes (EMD, 99.9\%), and silicone oil (Aldrich, $10 \mathrm{cSt}$ ) were used without further purification. 18.2 $\mathrm{M} \Omega$ water was obtained from a Millipore Milli-Q water purification system. Ammonium ferrocyanide heptahydrate $\left((\mathrm{NH})_{4} \mathrm{Fe}(\mathrm{CN})_{6} \cdot 7 \mathrm{H}_{2} \mathrm{O}\right)$ was prepared according to a literature procedure. ${ }^{1}$

\section{Instrumentation}

All electrochemistry experiments were performed using a BioLogic VMP3 potentiostat inside a VAC OMNI-LAB glovebox filled with nitrogen.

\section{Cyclic Voltammetry}

Six aqueous solutions were prepared: (a) $10 \mathrm{mg} \mathrm{mL}^{-1} \mathrm{Na}_{4} \mathrm{Fe}(\mathrm{CN})_{6} \cdot 10 \mathrm{H}_{2} \mathrm{O}$ and $0.5 \mathrm{M} \mathrm{NH}_{4} \mathrm{Cl}$; (b) $100 \mathrm{mg} \mathrm{mL}^{-1} \mathrm{PEG}, 10 \mathrm{mg} \mathrm{mL}^{-1} \mathrm{Na}_{4} \mathrm{Fe}(\mathrm{CN})_{6} \cdot 10 \mathrm{H}_{2} \mathrm{O}$, and $0.5 \mathrm{M} \mathrm{NH}_{4} \mathrm{Cl}$; (c) $100 \mathrm{mg} \mathrm{mL}^{-1} \mathrm{PEG}, 10$ $\mathrm{mg} \mathrm{mL}^{-1}$ PDADMAC, $10 \mathrm{mg} \mathrm{mL}^{-1} \mathrm{Na}_{4} \mathrm{Fe}(\mathrm{CN})_{6} \cdot 10 \mathrm{H}_{2} \mathrm{O}$, and $0.5 \mathrm{M} \mathrm{NH}_{4} \mathrm{Cl}$; (d) $10 \mathrm{mg} \mathrm{mL}^{-1} \mathrm{MV}$ and $0.5 \mathrm{M} \mathrm{NH}_{4} \mathrm{Cl}$; (e) $150 \mathrm{mg} \mathrm{mL}^{-1}$ dextran, $10 \mathrm{mg} \mathrm{mL}^{-1}$ (w/v) $\mathrm{MV}$, and $0.5 \mathrm{M} \mathrm{NH}_{4} \mathrm{Cl}$; (f) $150 \mathrm{mg}$ $\mathrm{mL}^{-1}$ dextran, $10 \mathrm{mg} \mathrm{mL}^{-1} \mathrm{PSS}, 10 \mathrm{mg} \mathrm{mL}^{-1} \mathrm{MV}$, and $0.5 \mathrm{M} \mathrm{NH}_{4} \mathrm{Cl}$. A $3 \mathrm{~mm}$ glassy carbon electrode was used as the working electrode. A Pt wire was used as the counter electrode. A 
$\mathrm{AgCl} / \mathrm{Ag}$ in $3.0 \mathrm{M} \mathrm{NaCl}$ electrode was used as the reference electrode. Cyclic voltammetry with scan rates of $10,20,50,100,200 \mathrm{mV} \mathrm{s}^{-1}$ was performed to each of the solutions. The diffusion coefficients of the active materials were evaluated by plotting peak current vs scan rate based on Randles-Sevcik equation:

$$
i_{\mathrm{p}}=0.4463 n F A c\left(\frac{n F v D}{R T}\right)^{\frac{1}{2}}
$$

where $i_{\mathrm{p}}$ is the peak current of cyclic voltammetry in $\mathrm{A} ; n$ is the number of electrons transferred in the redox event; $A$ is the electrode area in $\mathrm{cm}^{2} ; \mathrm{F}$ is the Faraday Constant in $\mathrm{C}^{-1} ; D$ is the diffusion coefficient in $\mathrm{cm}^{2} \mathrm{~s}^{-1} ; C$ is the concentration of the active material in mol $\mathrm{cm}^{-3} ; v$ is the scan rate in $\mathrm{V} \mathrm{s}^{-1}$; $\mathrm{R}$ is the universal gas constant in $\mathrm{J} \mathrm{K}^{-1} \mathrm{~mol}^{-1} ; T$ is the temperature in $\mathrm{K}$.

\section{Bulk prototype of all-aqueous batteries}

In a glovebox filled with nitrogen, two 3-mm glassy carbon electrodes were installed onto a custom-made electrochemical cell (Supplementary Figure 3a). A 10-ml aqueous solution containing 15\% (w/v) dextran, $1 \%(\mathrm{w} / \mathrm{v}) \mathrm{PSS}$, and $0.5 \mathrm{M} \mathrm{NH}_{4} \mathrm{Cl}$ was added to the bottom. Another $10-\mathrm{ml}$ aqueous solution containing $10 \%$ (w/v) PEG, $1 \%(w / v)$ PDADMAC, and $0.5 \mathrm{M} \mathrm{NH}_{4} \mathrm{Cl}$ was added carefully on the top of the first solution. The biphasic mixture was allowed to age overnight. $0.5 \mathrm{~mL}$ of the solution was carefully withdrawn from the bottom phase and used to dissolve $51.4 \mathrm{mg}(0.2 \mathrm{mmol})$ of MV. The solution was injected back to the bottom phase. $1 \mathrm{~mL}$ of the solution was taken from the top phase and used to dissolve $96.8 \mathrm{mg}(0.2 \mathrm{mmol})$ of $\mathrm{Na}_{4} \mathrm{Fe}(\mathrm{CN})_{6} \cdot 10 \mathrm{H}_{2} \mathrm{O}$. The solution was added slowly back to the top phase. The biphasic mixture was allowed to equilibrate overnight again. The battery was charged/discharged between 1 and $0 \mathrm{~V}$.

\section{Preparation of current collectors}

Micro slides (VWR, nominal 1" × 3") were cleaned using UV-ozone for 20 min and covered by polyimide tape. The tape was carved into the designed shape (Supplementary Figure 3a and c) 
using a razor blade. A $5 \mathrm{~nm}$ layer of $\mathrm{Cr}$ and a $100 \mathrm{~nm}$ layer of $\mathrm{Ag}$ was deposited sequentially on the exposed surface using a thermal evaporator at $0.05-0.1 \mathrm{~nm} \mathrm{~s}^{-1}$ and $0.2-0.5 \mathrm{~nm} \mathrm{~s}^{-1}$, respectively. The metal coating was aged for at least $24 \mathrm{~h}$. The polyimide tape was carefully removed after being rinsed by chloroform. The slides were flipped and immersed in $0.1 \%$ PFOTS in hexanes for $1 \mathrm{~min}$. The treated slides were rinsed extensively with acetone. After the slides became dry, a $1 \% 3$ mercaptopropionic acid aqueous solution was deposited on top of the Ag surface. After the slides standing for $1 \mathrm{~min}$, the aqueous solution was removed. The treated surface was washed extensively with water. Then, a $1 \%$ ammonia solution was used to neutralize the surface. The unreacted ammonia was rinsed away with water and let dry.

\section{Assembly of Patterned All-Liquid Electrochemical Devices}

The treated glass slides with current collectors were transferred into a glove box and placed inside a $30 \mathrm{~mm} \times 76 \mathrm{~mm}$ rectangular glass dish. The glass dish was placed inside a plastic container with two holes in the lid. Two open vials of water were placed inside the container to create a moist environment. An aqueous solution containing $100 \mathrm{mg} \mathrm{mL}^{-1}$ PEG, $10 \mathrm{mg} \mathrm{mL}^{-1}$ PDADMAC, and $0.5 \mathrm{M} \mathrm{NH}_{4} \mathrm{Cl}$ was added slowly to one current collector. Another aqueous solution containing 150 $\mathrm{mg} \mathrm{mL} \mathrm{m}^{-1}$ dextran, $10 \mathrm{mg} \mathrm{mL}^{-1} \mathrm{PSS}$, and $0.5 \mathrm{M} \mathrm{NH}_{4} \mathrm{Cl}$ was added simultaneously to the other current collector. The two solutions were added until they merged on the gap between the two current collectors. $0.45 \mathrm{ml}$ each of the solutions were consumed. Silicone oil were added on the top of aqueous solutions until the aqueous phase was thoroughly immersed. The two current collectors were respectively connected to the $\mathrm{WE}$ and $\mathrm{CE} / \mathrm{RE}$ clamps using silver rods. The polyelectrolyte solutions were allowed to age overnight. $\left(\mathrm{NH}_{4}\right)_{4} \mathrm{Fe}(\mathrm{CN})_{6} \cdot 7 \mathrm{H}_{2} \mathrm{O}$ and $\mathrm{MV}$ were dissolved in the aforementioned PEG solution and dextran solution, respectively, and added 
carefully to their corresponding phases to make the final concentration of active materials in each phase at $0.2 \mathrm{M}$. The active materials were allowed to diffuse for $24 \mathrm{~h}$ before charge and discharge.

\section{Electrochemical Methods}

The cell was charged galvanostatically until a potential limit of $1.0 \mathrm{~V}$, or until the theoretical capacity was reached, after which the cell was allowed to rest for $2 \mathrm{~h}$. The cell was then discharged galvanostatically until a potential limit of $0.2 \mathrm{~V}$. A constant voltage discharge at $0.2 \mathrm{~V}$ was applied until the current dropped below $3 \mu \mathrm{A}$. The cell was subsequently allowed to rest for $2 \mathrm{~h}$ before initiating the next cycle.

\section{Analysis of Active Material Crossover}

After cell cycling, the silicone oil was removed from the cell holder. The all-aqueous cell turned into a piece of thin, soft film within $15 \mathrm{~min}$. The film was peeled off completely from the current collectors and cut at the interface of the two phases. Each of the two phases were diluted with 0.5 $\mathrm{M} \mathrm{NH} 4 \mathrm{Cl}$ in volumetric flasks to $5.0 \mathrm{~mL}$. Cyclic voltammetry was used to measure the concentration of MV in the PEG phase and ferrocyanide in the dextran phase. Calibration curves were established by adding MV into the PEG phase and ferrocyanide into the dextran phase. To make the PEG phase, $41.0 \mathrm{mg}$ of $(\mathrm{NH})_{4} \mathrm{Fe}(\mathrm{CN})_{6} \cdot 7 \mathrm{H}_{2} \mathrm{O}, 134 \mathrm{mg}$ of $\mathrm{NH}_{4} \mathrm{Cl}, 6.0 \mathrm{mg} / 30 \mu \mathrm{L}$ of PDADMAC $20 \%$ solution, and $60 \mathrm{mg}$ of PEG were diluted to $5.0 \mathrm{~mL}$. To make the dextran phase, $25.7 \mathrm{mg}$ of $\mathrm{MV}, 134 \mathrm{mg}$ of $\mathrm{NH}_{4} \mathrm{Cl}, 6.0$ of PSS, and $90 \mathrm{mg}$ of dextran were diluted to $5.0 \mathrm{~mL} .12 .8$ mg of MV was dissolved in $25 \mu \mathrm{L}$ of the PEG phase and added into the remaining PEG phase in $2.5 \mu \mathrm{L}$ increments corresponding to $5.2 \%, 10.4 \%, 15.5 \%, 20.6 \%, 25.6 \%, 30.6 \%, 35.5 \%, 40.4 \%$, and $45.2 \%$ crossover of MV. $20.5 \mathrm{mg}$ of $(\mathrm{NH})_{4} \mathrm{Fe}(\mathrm{CN})_{6} \cdot 7 \mathrm{H}_{2} \mathrm{O}$ was dissolved in $25 \mu \mathrm{L}$ of the 
dextran phase and added into the remaining dextran phase in $2.5 \mu \mathrm{L}$ increments corresponding to $5.2 \%, 10.4 \%, 15.5 \%, 20.6 \%, 25.6 \%, 30.6 \%, 35.5 \%, 40.4 \%$, and $45.2 \%$ crossover of ferrocyanide.

\section{Calculation of the effective diffusion coefficient across the membrane}

The effective diffusion coefficient, $D_{\text {eff, }}$ was calculated based on an equation previously reported: ${ }^{2}$

$$
D_{\text {eff }}=\frac{C_{\text {perm }}(t) l V}{C_{0} A t}
$$

where $C_{\text {perm }}$ and $C_{0}=0.2 \mathrm{M}$ are the permeated and initial concentrations of the active materials, respectively; $l$ is the thickness of the coacervate membrane; $V=0.5 \mathrm{~cm}^{3}$ is the volume of the electrolyte; $A=0.16 \mathrm{~cm}^{2}$ is the surface area of the membrane; $t=3.27 \times 10^{6} \mathrm{~s}$ is the time between addition of active materials and disassembly of the cell. $C_{\text {perm }} / C_{0}$ was measured by post-mortem cyclic voltammetry, vide supra. 


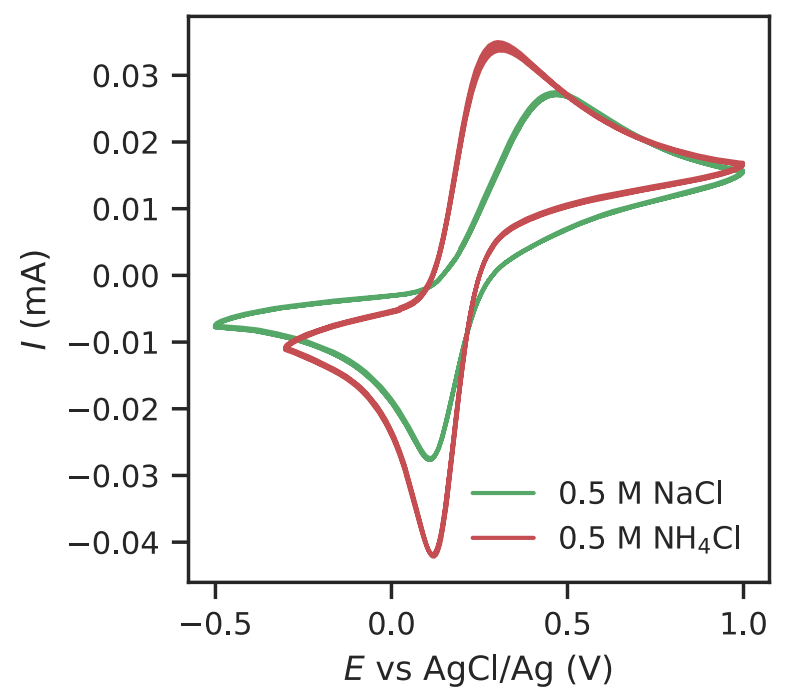

Fig. S1. Redox reversibility of ferrocyanide | Comparison of ferrocyanide in $\mathrm{NaCl}$ or $\mathrm{NH}_{4} \mathrm{Cl}$ as supporting electrolyte: $0.5 \mathrm{M}$ supporting electrolyte, 10\% PEG, and 1\% PDADMA-Cl at 20 $\mathrm{mV} / \mathrm{s}$. 

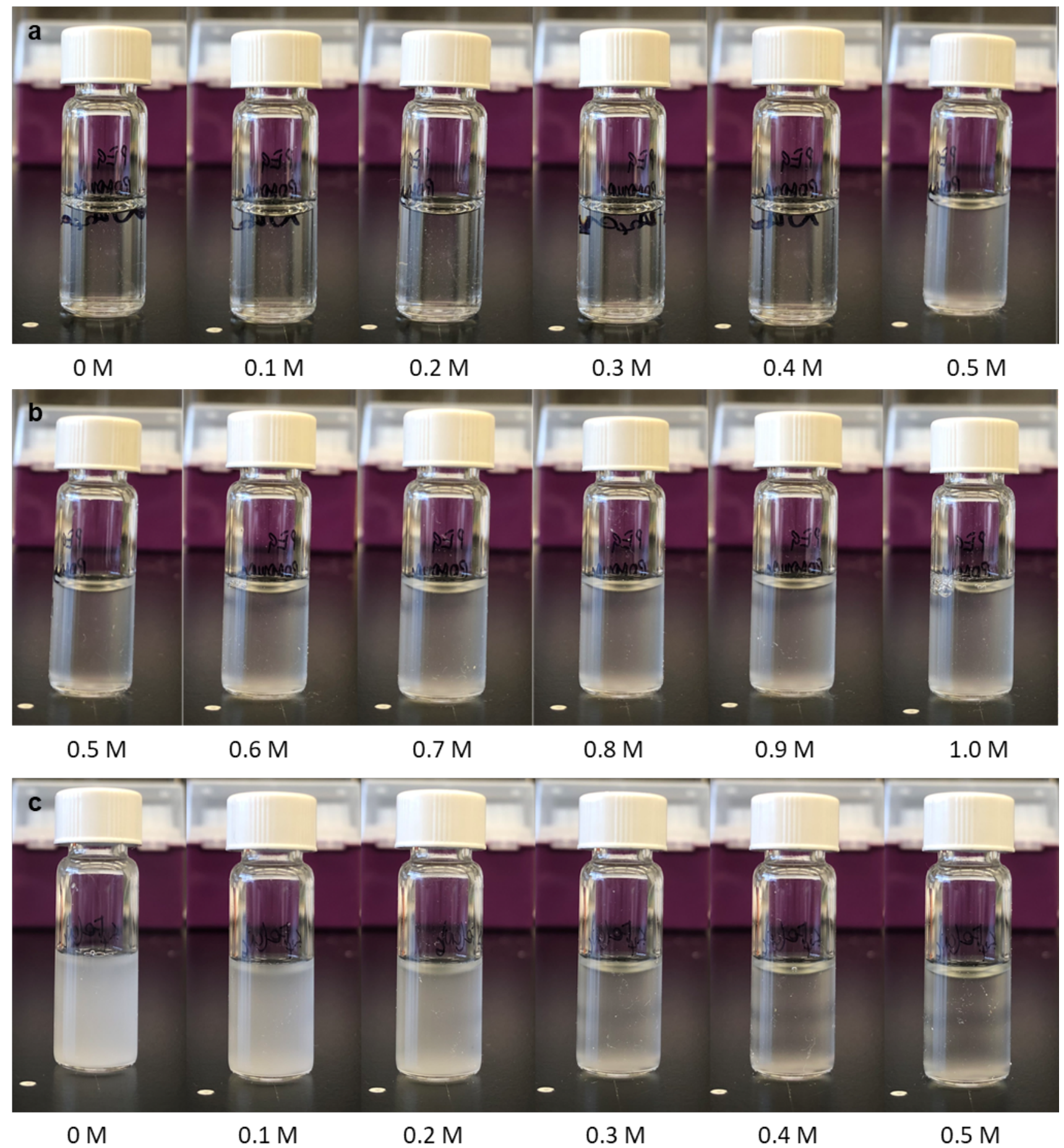

Fig. S2. Colloidal stability of PEG solutions with $\mathrm{NH}_{4} \mathbf{C l} \mid \mathbf{a}$ and $\mathbf{b}$. $\mathrm{NH}_{4} \mathrm{Cl}$ concentration series in an aqueous solution containing 1\% PDADMAC and 10\% PEG. c. $\mathrm{NH}_{4} \mathrm{Cl}$ concentration series in an aqueous solution containing $0.016 \mathrm{M}$ ferrocyanide, 1\% PDADMAC, and 10\% PEG 

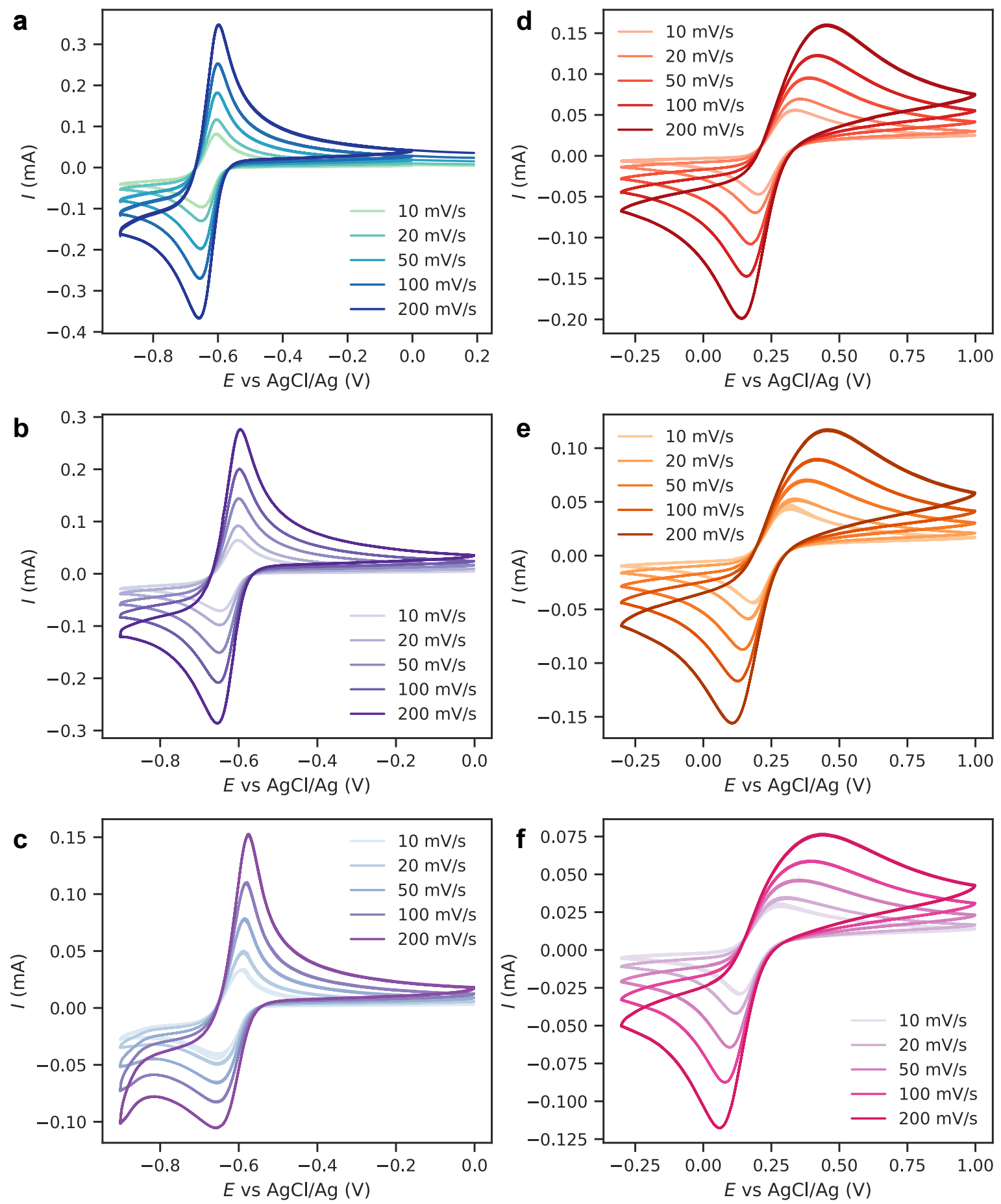

Fig. S3. Cylic voltammetry of active materials | a-c. Cyclic voltammetry of methyl viologen aqueous solutions without polymer additives (a), with 15\% dextran (b), and with $15 \%$ dextran and $1 \%$ PSS (c). d-f. Cyclic voltammetry of ferrocyanide aqueous solutions without polymer additives (d), with 10\% PEG (e), and with 10\% PEG and 1\% PDADMAC (f). Working electrode: $3 \mathrm{~mm}$ glassy carbon; counter electrode: Pt wire; reference electrode: $\mathrm{AgCl} / \mathrm{Ag}$ in $3.0 \mathrm{M} \mathrm{NaCl}$; supporting electrolyte: $0.5 \mathrm{M} \mathrm{NH}_{4} \mathrm{Cl}$. 

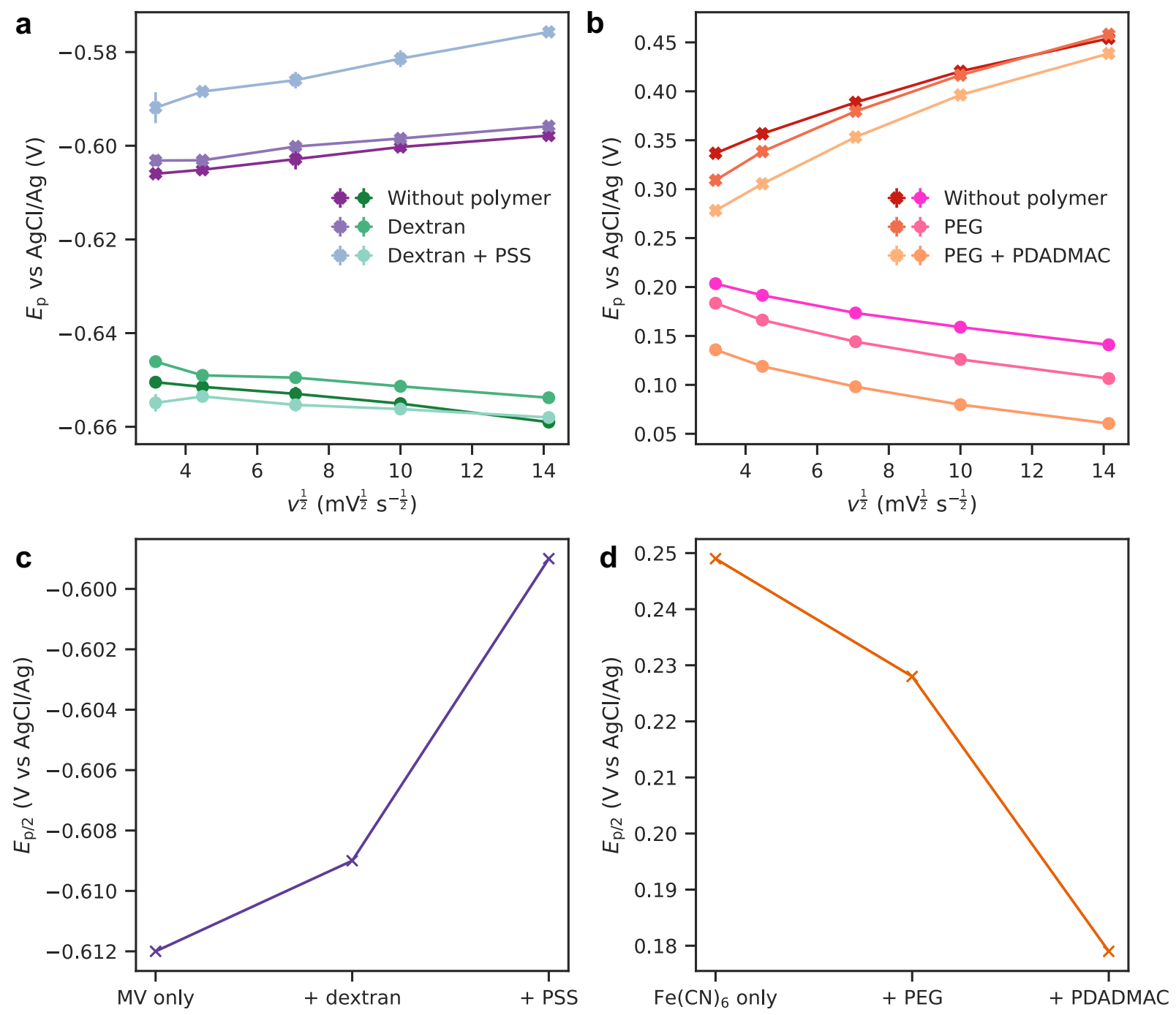

Fig. S4. Cathodic and anodic peak potentials of the active materials with or without polymer additives $\mid$ a \& c. Methyl viologen. b \& d. Ferrocyanide. a \& b. Peak potential vs. scan rate of active materials with or without polymer additives. $\mathbf{c} \& \mathbf{d}$. Half peak potential of the two active materials with or without polymer additives at $20 \mathrm{mV} \mathrm{s}^{-1}$. Working electrode: $3 \mathrm{~mm}$ glassy carbon; counter electrode: Pt wire; reference electrode: $\mathrm{AgCl} / \mathrm{Ag}$ in $3.0 \mathrm{M} \mathrm{NaCl}$; supporting electrolyte: $0.5 \mathrm{M} \mathrm{NH}_{4} \mathrm{Cl}$. Error bars: SD of five continuous scans after the first one. 


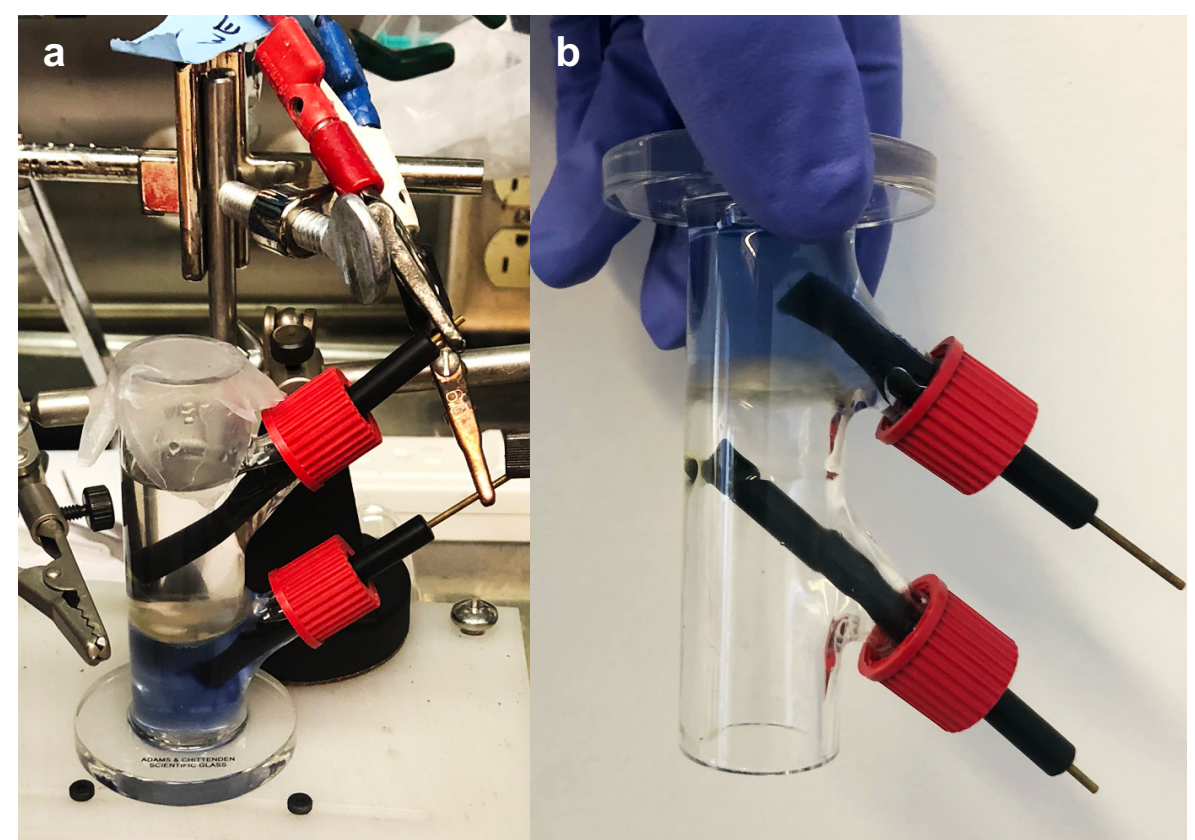

Fig. S5. Formation of polyelectrolyte coacervate | a. Cycling of a bulk prototype of all-aqueous electrochemical cell. b. Inverted electrochemical cell after cycling for 4 days. 
a

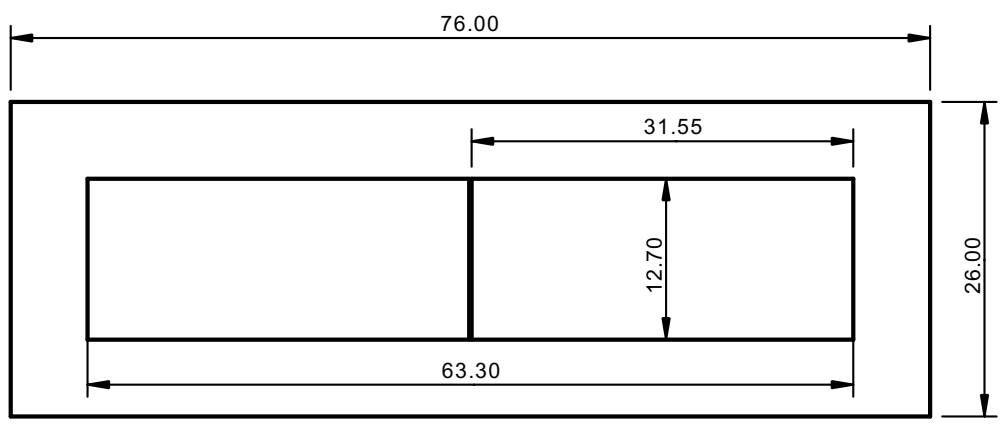

b
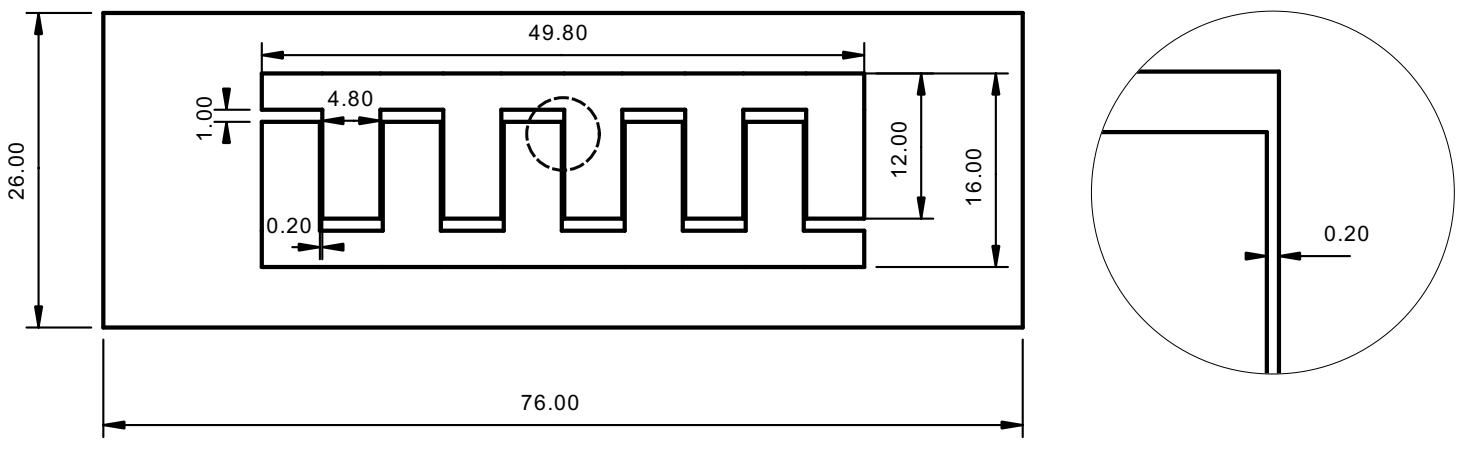

C

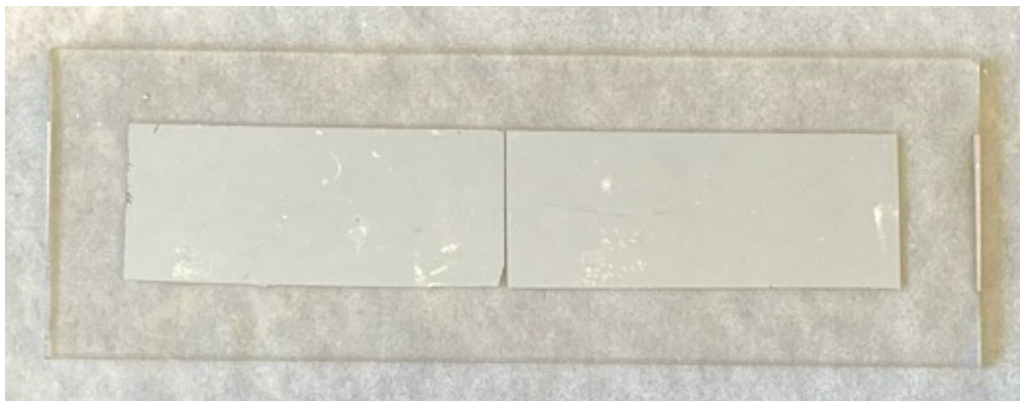

d

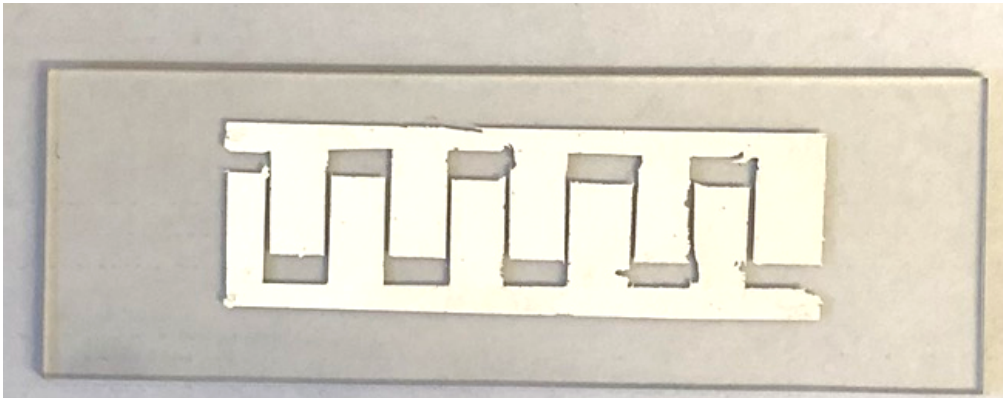

Fig. S6. Design of current collectors | a-b. Technical drawing of parallel bocks (a) and interdigitated arrays (b). c-d. Photos of fabricated current collectors. 


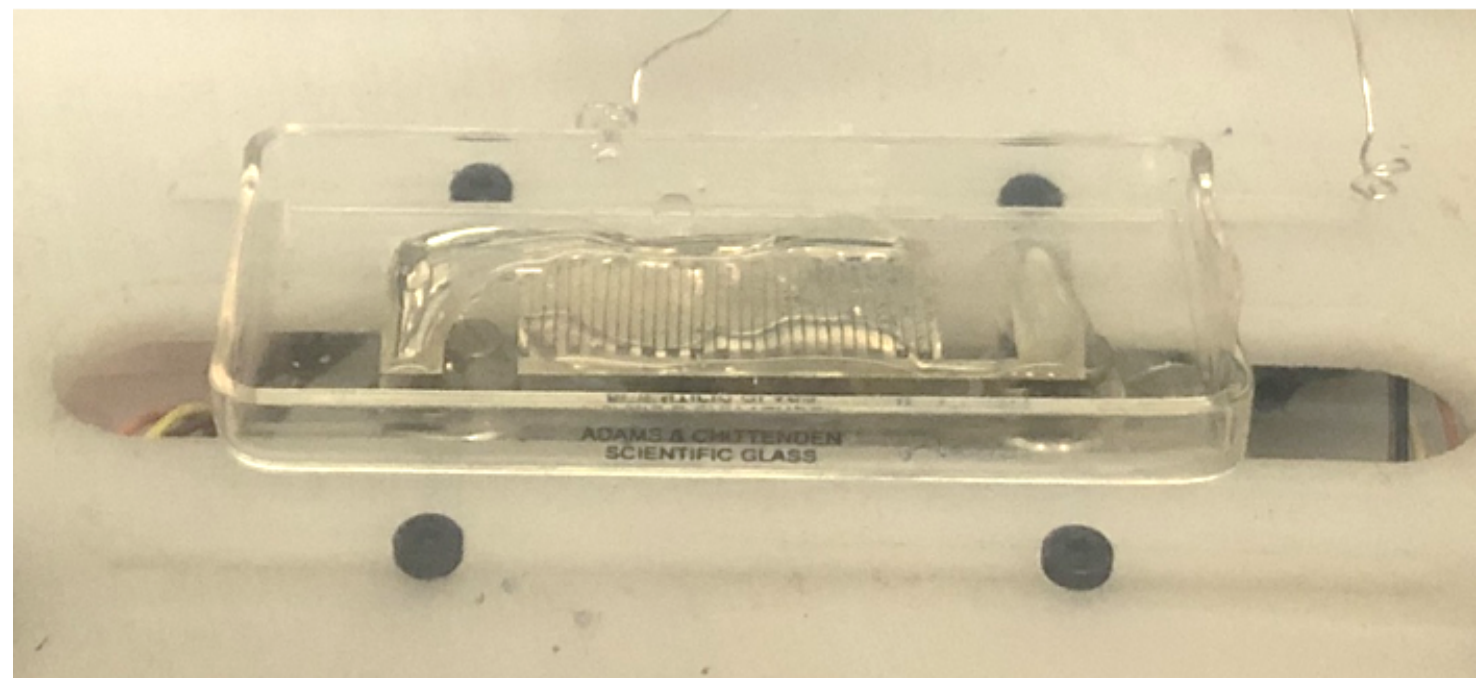

Fig. S7. Wetting on conventional interdigitated array 


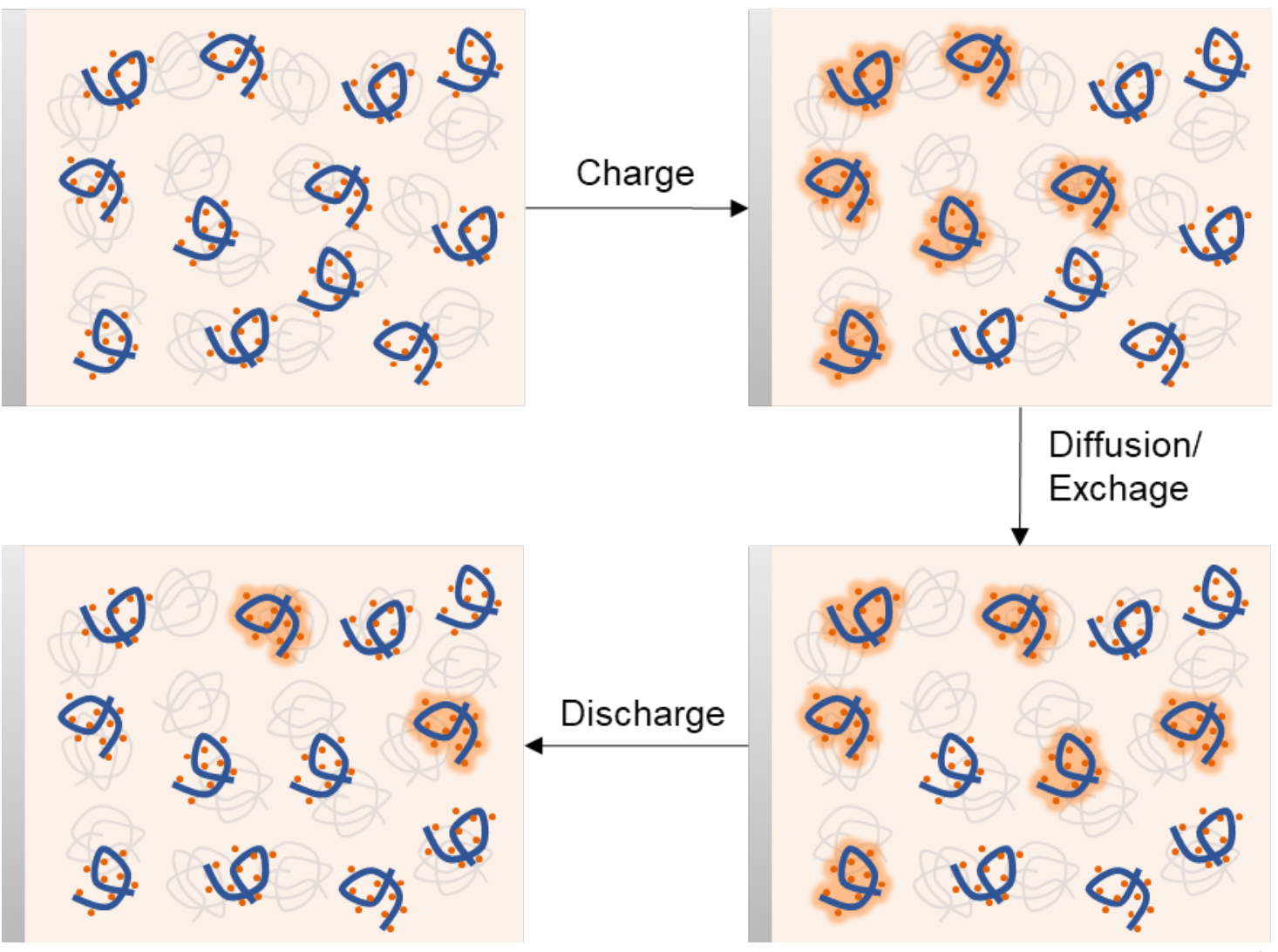

Fig. S8. Illustration of the evolution of active material complexes in a cell. Active species (orange dots) forms complexes with polyelectrolytes (blue coils) with the opposite charge. Charged complexes are indicated with a glow. The silver plate on the left represents the current collector. 

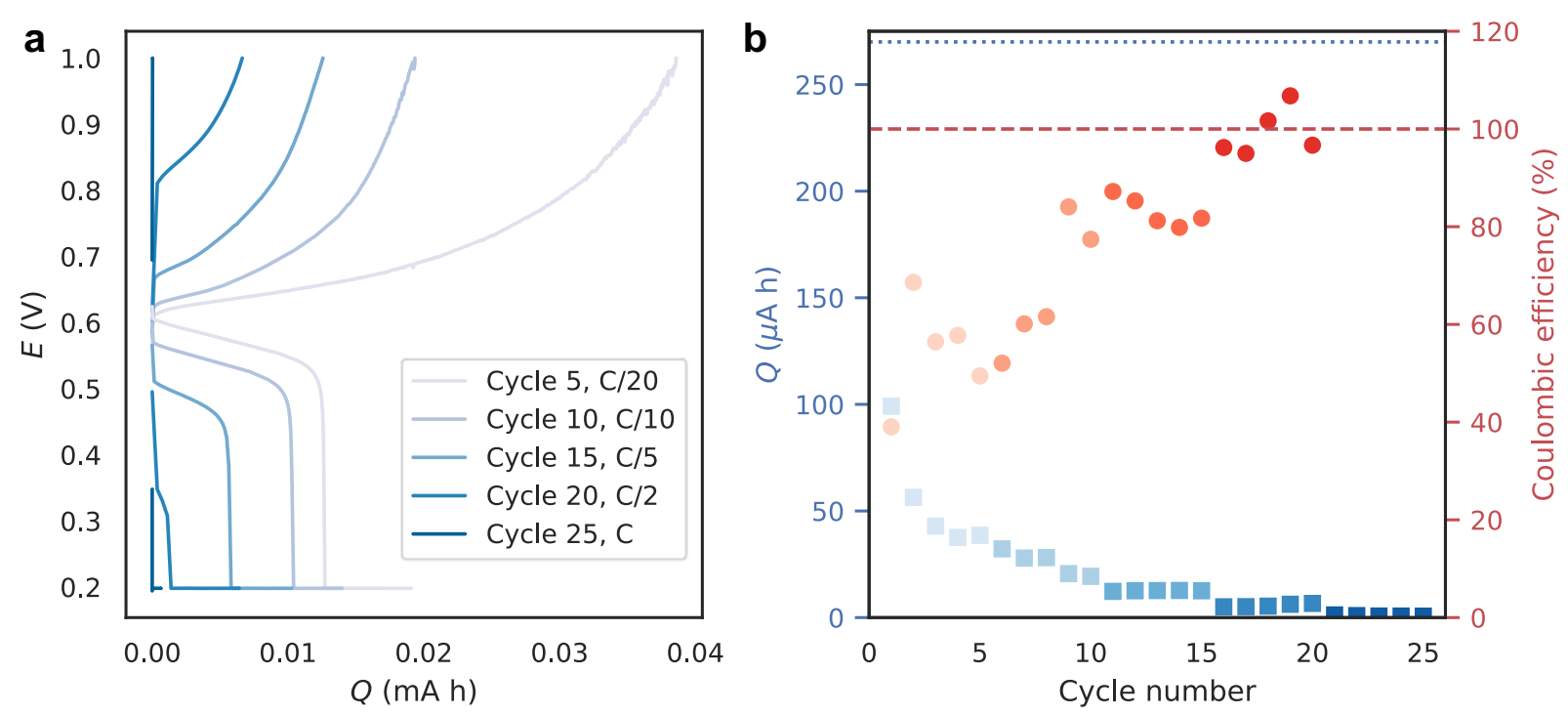

Fig. S9. Under-oil all-aqueous electrochemical cell with an interdigitated array architecture | a. Charge and discharge potential vs. capacity at the $5^{\text {th }}, 10^{\text {th }}, 15^{\text {th }}, 20^{\text {th }}$, and $25^{\text {th }}$ cycle. b. Columbic efficiency and accessed capacity of each cycle. The red dashed line indicates the theoretical capacity. In each cycle, the cell was charged/discharged at a constant current of 13.5, $27,54,135$, and $270 \mu \mathrm{A}$ for 5 cycles each up to the potential limits of $1.0 \mathrm{~V}$ and $0.2 \mathrm{~V}$, respectively, or up to $5 \mathrm{~h}$. A constant voltage discharge for up to $5 \mathrm{~h}$ with a cutoff current of $3 \mu \mathrm{A}$. After charge/discharge, the cell was rested for $2 \mathrm{~h}$. 

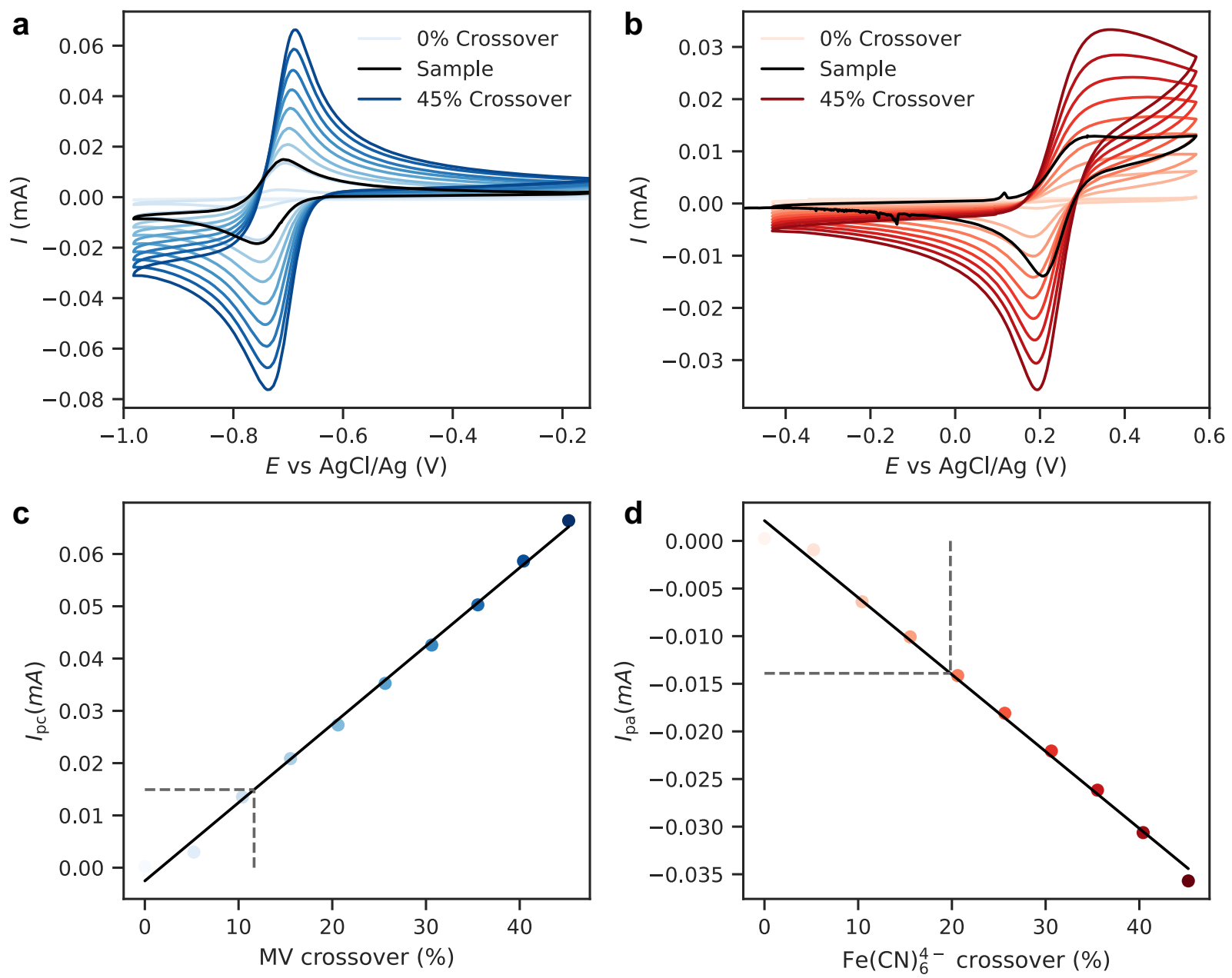

Fig. S10. Crossover analysis after cycling | a. Cyclic voltammetry of the methyl viologen in the poly(ethylene glycol) phase. Black lines shows the diluted poly(ethylene glycol) phase after cycling. Blue lines shows the calibration samples of methyl viologen in the poly(ethylene glycol) phase with methyl viologen concentrations adjusted to $5,10,15,20,25,30,35,40$, and 45\% crossover. b. Cyclic voltammetry of the ferrocyanide in the dextran phase. Black lines shows the diluted dextran phase after cycling. Red lines shows the calibration samples of ferrocyanide in the dextran phase with ferrocyanide concentrations adjusted to $5,10,15,20,25,30,35,40$, and 45\% crossover. c. Calibration curve of cathodic peak current vs. the predicted crossover percentage from panel a (blue scatter) and the corresponding linear fitting. d. Calibration curve of anodic peak current vs. the predicted crossover percentage from panel b (blue scatter) and the corresponding linear fitting. 


\section{Reference}

1. J. Luo, B. Hu, C. Debruler, Y. Bi, Y. Zhao, B. Yuan, M. Hu, W. Wu, T. L. Liu, Joule 2019, 3, 149-163.

2. S. E. Doris, A. L. Ward, A. Baskin, P. D. Frischmann, N. Gavvalapalli, E. Chénard, C. S. Sevov, D. Prendergast, J. S. Moore, B. A. Helms, Angew. Chem. Int. Ed. 2017, 56, 1595-1599. 